SUPPORTING INFORMATION FOR

\title{
Binary Protein Crystals for the Assembly of Inorganic Nanoparticle Superlattices
}

\author{
Matthias Künzle, ${ }^{\dagger}$ Thomas Eckert, ${ }^{\ddagger}$ and Tobias Beck ${ }^{\star, \dagger}$ \\ ${ }^{\dagger}$ Institute of Inorganic Chemistry, RWTH Aachen University, Landoltweg 1, 52074 Aachen, \\ Germany \\ ${ }^{\ddagger_{\text {Institute }}}$ of Physical Chemistry, RWTH Aachen University, Landoltweg 2, 52074 Aachen, \\ Germany \\ *Email: tobias.beck@ac.rwth-aachen.de
}

Page

Materials and Methods $\quad$ S2

$\begin{array}{ll}\text { References } & \text { S16 }\end{array}$

Supplementary Tables and Figures

Figure S1: Computational design with Rosetta fixbb module for $\mathrm{Ftn}^{(\text {neg) }} \quad \mathrm{S} 17$

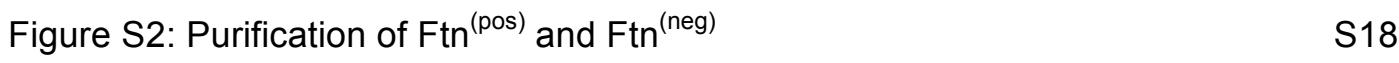

Figure S3: Microscopy images of binary crystals $\quad$ S19

Table S1: Crystallographic data for binary crystal structures of $\mathrm{Ftn}^{\text {(pos) }}$ and $\mathrm{Ftn}^{(\mathrm{neg})} \mathrm{S} 20$

Figure S4: Electron density omit maps for mutations in $\mathrm{Ftn}^{\left({ }^{(\mathrm{pos})}\right.}$ and $\mathrm{Ftn}^{(\text {neg) }} \quad$ S21

Figure S5: Contacts between protein containers in the binary crystal structures S22

Figure S6: Metal oxide nanoparticle synthesis in $\mathrm{Ftn}^{\left({ }^{(\mathrm{pos})}\right.}$ and $\mathrm{Ftn}^{\left({ }^{(\mathrm{neg})}\right.} \quad \mathrm{S} 23$

Figure S7: Protein container nanoparticle composites with Ftn ${ }^{\text {(pos) }} \quad$ S24

Figure S8: Protein container nanoparticle composites with Ftn ${ }^{\left({ }^{n e g}\right)} \quad$ S25

Table S2: Size of protein container nanoparticle composites $\quad$ S26

$\begin{array}{ll}\text { Figure S9 and Table S3: Selected area electron diffraction of } \mathrm{Co}_{3} \mathrm{O}_{4} & \mathrm{~S} 27\end{array}$

Figure S10 and Table S4: Selected area electron diffraction of $\mathrm{CeO}_{2} \quad$ S28

Table S5: Selected nanoparticle combinations in binary crystals $\quad$ S29

Figure S11: Microscopy images of binary protein-nanoparticle crystals $\quad$ S30

Figure S12: Microscopy images of binary protein-nanoparticle crystals $\quad$ S31

Figure S13: SEM analysis of binary crystals $\quad$ S32

Table S6: Cell parameters obtained from SAXS data S33

Figure S14: SAXS data of binary crystals composed of empty containers $\quad$ S34

Figure S15: SAXS data of binary protein-nanoparticle crystals $\quad$ S35 


\section{Computational design}

The computational design and gene construction of $\mathrm{Ftn}^{(\mathrm{neg})}$ followed closely the procedure for $\mathrm{Ftn}^{\left({ }^{(\mathrm{pos})}\right.}$ as described before. ${ }^{[1]}$

The Rosetta molecular modeling program (version 3.4) ${ }^{[2]}$ was used to identify potential sites in human heavy chain ferritin to create a negatively charged protein container. Simulations were carried out with the fixbb protocol within Rosetta, similar to the approach by Miklos et al ${ }^{[3]}$, on a model file derived from the crystal structure (PDB ID 2CEI) after energy minimization within Rosetta. For ferritin, six additional neighboring monomers were included in the simulations by employing a symmetry definitions file. Residues that were allowed to be mutated included residues on the outer container surface, but not those on the inner surface or in intermolecular contacts with other subunits. During simulations the native amino acid, aspartic or glutamic acid were allowed. Following rotamer optimization by simulated annealing, side chains were further optimized by gradient-based optimization in Rosetta. Simulations were run with a stepwise increase of the reference energies for Asp and Glu (Fig. S1). For each run, 500 trajectories with the same starting parameters were calculated. The trajectory with the lowest Rosetta energy score was selected for each set of parameters and is shown in the sequence alignment (Fig. S1). Mutation sites and the electrostatic potential for each run were inspected with the program PyMOL (DeLano Scientific LLC). Because with mutations from run01 the electrostatic potential of the variant is already highly negative, the sequence $\mathrm{Ftn}^{(\text {neg) }}$ that was selected for subsequent experiments is based on run01 (highlighted in red, Fig. S1). However, suggestions for mutation close to the three-fold channel (T122E) as well as for mutation to a similarly charged amino acid (D123E) were not considered. Mutations for variant $\mathrm{Ftn}^{(\mathrm{neg})}$ are A18E, C90E, C102E, H105E. Mutations to positively charged amino acids were already carried out at these sites for the positively charged variant $\mathrm{Ftn}^{(\text {pos) }}{ }^{[1]}$

\section{Molecular cloning of Ftn $^{(\text {neg) }}$}

Mutations were introduced into the wild-type gene of human heavy chain ferritin with mismatched mutagenesis primers using overlap-extension-PCR. All PCRs were carried out on a PTC200 Peltier Thermal Cycler (MJ Research). DNA fragments were amplified ( 32 cycles with denaturation for $30 \mathrm{~s}$ at $98^{\circ} \mathrm{C}$, annealing for $30 \mathrm{~s}$ at $55^{\circ} \mathrm{C}$, 
and elongation for $45 \mathrm{~s}$ at $72{ }^{\circ} \mathrm{C}$; followed by 1 cycle elongation for $600 \mathrm{~s}$ at $72{ }^{\circ} \mathrm{C}$ ) using the primer pairs pAKZ3 / Ala18Glu_rev (fragment 1: no mismatch, 5'-GAT CCC GCG AAA TTA ATA CGA CTC ACT ATA GG / 5' -TTC CGA ATC CTG GTG G), Ala18Glu_for / bridge_Cys90Glu_rev (fragment 2: 1 codon mismatch, 5'CCA CCA GGA TTC GGA AGA AGC AAT CAA TCG TCA GAT CAA TCT GG / 5'-ATC GGG CTT CTG AAT ATC TTG C) and Cys102Glu_for / T7TR (fragment 3: 2 codon mismatches, 5'-GCT TAA ATG CTA TGG AAG AAG CAC TGG AAC TTG AGA AGA ACG TCA ACC / 5' -TGC TAG TTA TTG CTC AGC GG) with pET-wtFtn as template (50 ng). The wild type gene was previously subcloned into pET-PATCH ${ }^{[4]}$ (a kind gift of the laboratory of Prof. Donald Hilvert). The bridging fragment bridge_Cys90Glu_for (1 codon mismatch, 5'-GCA AGA TAT TCA GAA GCC CGA TGA AGA TGA TTG GGA ATC TGG CTT AAA TGC) was used to connect fragment 2 and 3. Assembly PCR (50 ng of each DNA fragment; assembly step: 5 cycles with denaturation for $30 \mathrm{~s}$ at $98^{\circ} \mathrm{C}$, annealing for $30 \mathrm{~s}$ at $55^{\circ} \mathrm{C}$, and elongation for $45 \mathrm{~s}$ at $72{ }^{\circ} \mathrm{C}$; amplification step after addition of primers pAKZ3 and T7TR: 32 cycles with denaturation for $30 \mathrm{~s}$ at $98{ }^{\circ} \mathrm{C}$, annealing for $30 \mathrm{~s}$ at $57^{\circ} \mathrm{C}$, and elongation for $45 \mathrm{~s}$ at $72{ }^{\circ} \mathrm{C}$; followed by 1 cycle elongation for $600 \mathrm{~s}$ at $72{ }^{\circ} \mathrm{C}$ ) yielded the complete $\mathrm{ftn}$ gene with all four mutations, termed $f \mathrm{tn}^{(n e g)}$. The gene was purified via agarose gel electrophoresis, extracted from the gel with the NucleoSpin Gel and PCR Clean-up kit (Macherey-Nagel) according to the manufacturer's instructions and cloned into pET-PATCH via the NdeI and XhoI restriction sites (ligation: $50 \mathrm{ng}$ insert DNA, $100 \mathrm{ng}$ dephosphorylated vector DNA; incubation overnight at $16{ }^{\circ} \mathrm{C}$ with $1 \mu \mathrm{L}$ T4 DNA ligase (Fermentas) and T4 DNA ligase buffer (Fermentas); $10 \mu \mathrm{L}$ of the ligation mix were directly transformed by heat-shock into $\mathrm{CaCl}_{2}$-treated E. coli XL1-Blue cells to produce the target plasmid pET-ftn $^{(n e g)}$ with mutations: A18E, C90E, C102E, H105E).

For plasmid amplification, single colonies of transformed XL1-Blue cells were incubated overnight in $5 \mathrm{~mL}$ sterile LB-Miller medium supplemented with $150 \mu \mathrm{g} / \mathrm{mL}$ sodium ampicillin at $37^{\circ} \mathrm{C}$ and $250 \mathrm{rpm} .4 \mathrm{~mL}$ were used for plasmid purification with the NucleoSpin plasmid purification kit (Macherey-Nagel) according to the manufacturer's instructions. Plasmid DNA was eluted in $50 \mu \mathrm{L}$ sterile $\mathrm{H}_{2} \mathrm{O}$ milliQ. DNA concentrations were determined with a NanoDrop 2000 spectrophotometer 
(Thermo Scientific) based on $260 \mathrm{~nm}$ absorbance. $15 \mu \mathrm{L}$ of the solution were sequenced to confirm the introduced mutations.

\section{Production and purification of charged ferritin variants}

Ftn $^{\text {(pos) }}$ (previously referred to as FtnQC12 $2^{[1]}$ ): For precultures, single colonies of transformed E. coli BL21-Gold(DE3) cells (Agilent) were incubated overnight in $5 \mathrm{~mL}$ sterile LB-Miller medium supplemented with $150 \mu \mathrm{g} / \mathrm{mL}$ sodium ampicillin at $37^{\circ} \mathrm{C}$ and $250 \mathrm{rpm} .400 \mathrm{~mL}$ LB-Miller medium with $150 \mu \mathrm{g} / \mathrm{mL}$ sodium ampicillin were inoculated with $4 \mathrm{~mL}$ of the preculture and incubated at $37^{\circ} \mathrm{C}$ and $230 \mathrm{rpm}$. Protein overexpression was induced with isopropyl $\beta$-D-1-thiogalactopyranoside (final concentration: $0.25 \mathrm{mM}$ ) after reaching an $\mathrm{OD}_{600}$ of 0.2. Following induction, cultures were incubated at $37^{\circ} \mathrm{C}$ for $5 \mathrm{~h}$. Cells were harvested by centrifugation for 20 min at $4{ }^{\circ} \mathrm{C}$ and 5,000 g with a Sorvall RC 6 Plus centrifuge (Thermo Scientific). Pellets were washed with buffer A (50 mM Tris, $\mathrm{pH} 7.5,1 \mathrm{M} \mathrm{NaCl})$ and stored at $-20{ }^{\circ} \mathrm{C}$.

For purification, pellets from $400 \mathrm{~mL}$ culture were resuspended in $10 \mathrm{~mL}$ buffer A and sonicated $4 \times 1$ min on ice (60\% amplitude) with a Vibra-Cell VCX-130 ultrasonic processor (Sonics). The suspension was centrifuged for $20 \mathrm{~min}$ at 14,000 $\mathrm{g}$ and $4{ }^{\circ} \mathrm{C}$. The lysate supernatant was incubated with $1.5 \mathrm{mg} / \mathrm{mL}$ RNase A (AppliChem) for $3 \mathrm{~h}$ at $37^{\circ} \mathrm{C}$. Note that incomplete digestion of RNA resulted in significantly lower binding to the cation exchange column in later purification steps. Subsequently, the solution was heated to $65^{\circ} \mathrm{C}$ for $10 \mathrm{~min}$ in a water bath. Denatured E. coli proteins were separated by centrifugation for $20 \mathrm{~min}$ at $14,000 \mathrm{~g}$ and $4{ }^{\circ} \mathrm{C}$. The supernatant was subjected to precipitation with ammonium sulfate at a final concentration of $70 \%$ of its saturation, followed by centrifugation for $20 \mathrm{~min}$ at $14,000 \mathrm{~g}$ and $4{ }^{\circ} \mathrm{C}$. The pellet was redissolved in $10 \mathrm{~mL}$ buffer $\mathrm{A}$ and precipitated with ammonium sulfate and centrifuged as before for further removal of nucleic acids. The pellet was then dissolved in $50 \mathrm{~mL}$ buffer $\mathrm{B}$ (50 mM MES, pH 6, $0.5 \mathrm{M} \mathrm{NaCl}$ ) and filtered with a $0.22 \mu \mathrm{m}$ syringe filter (TPP). Subsequent ion exchange and gel filtration chromatography were performed on an ÄKTAprime plus chromatography system (GE Healthcare). The sample was purified on a $5 \mathrm{~mL}$ Sepharose HiTrap SP HP cation exchange column (GE Healthcare) with an elution gradient from 0.5 to 1.5 $\mathrm{M} \mathrm{NaCl}$. The $\mathrm{Ftn}^{(\mathrm{pos})}$-containing fractions were then concentrated with an Amicon 
Ultra-15 centrifugal filter unit (30 kDa MWCO; Merck Millipore) to $2 \mathrm{~mL}$ final volume and further purified on a HiLoad 16/600 Superdex 200 PG gel filtration column (GE Healthcare) in buffer A to remove higher-order oligomers and aggregates. For ferritin samples without nanoparticle core used in crystallization setups the gel filtration step was done twice for even higher purity (see Fig. S2). The fractions containing the ferritin monomer were then rebuffered at least five times with a centrifugal filter unit to the respective buffer for further experiments. Protein purity was further analyzed by Tricine-SDS-PAGE (Fig. S2), protein concentration was determined with a NanoDrop 2000 spectrophotometer (Thermo Scientific) and by the Bradford method, ${ }^{[5]}$ and protein mass was verified by MALDI-TOF-MS.

Ftn $^{(\mathbf{n e g})}$ : Protein production was similar to $\mathrm{Ftn}^{(\mathrm{pos})} .200 \mathrm{~mL}$ TB-medium were inoculated with $2 \mathrm{~mL}$ of preculture and grown to an $\mathrm{OD}_{600}$ of $0.6-0.7$ at $37^{\circ} \mathrm{C}$ and $230 \mathrm{rpm}$. Protein overexpression was induced with $0.25 \mathrm{mM}$ IPTG and cells were incubated at $18{ }^{\circ} \mathrm{C}$ for $48 \mathrm{~h}$. After harvesting, the pellets were washed with buffer $\mathrm{C}$ (50 mM Tris, $\mathrm{pH} 7.5,0.3 \mathrm{M} \mathrm{NaCl}$ ) and stored at $-20^{\circ} \mathrm{C}$.

Protein purification followed closely the protocol for $\mathrm{Ftn}^{(\mathrm{pos})}$ with minor changes. In detail, pellets from $200 \mathrm{~mL}$ culture were resuspended in buffer D (50 mM Tris, $\mathrm{pH} 7.5,0.15 \mathrm{M} \mathrm{NaCl}$ ) and sonicated $8 \times 1 \mathrm{~min}$ on ice. Heat precipitation at $65^{\circ} \mathrm{C}$ and two times precipitation by ammonium sulfate was done as for $\mathrm{Ftn}^{(\mathrm{pos})}$ while the RNA digest was omitted. For ion exchange chromatography, the protein was resuspended in $50 \mathrm{~mL}$ buffer $\mathrm{D}$ and purified by a linear gradient from 0.15 to $1 \mathrm{M} \mathrm{NaCl}$ using a $5 \mathrm{~mL}$ Sepharose HiTrap SP Q anion exchange column (GE Healthcare). Subsequent gel filtration and further treatment of the sample was the same as for $\mathrm{Ftn}^{(\mathrm{pos})}$ in buffer $\mathrm{C}$.

\section{Protein crystallography}

Crystallization. Suitable crystallization conditions were identified using commercial sparse matrix screening conducted at the Institute of Complex Systems (ICS-5), Molecular Biophysics, Forschungszentrum Jülich, with a Tecan Freedom Evo robot. Prior to crystallization setup, equal volumes of $\mathrm{Ftn}^{(\mathrm{pos})}$ in $50 \mathrm{mM}$ Tris, $\mathrm{pH} 7.5,1 \mathrm{M}$ $\mathrm{NaCl}$ and $\mathrm{Ftn}^{(\text {neg) }}$ in $50 \mathrm{mM}$ Tris, $\mathrm{pH} 7.5,0.3 \mathrm{M} \mathrm{NaCl}$ were mixed at a concentration of $4 \mathrm{mg} / \mathrm{mL}$ for each variant. 96-well plates for sitting drop vapor diffusion were set up with drops consisting of $0.5 \mu \mathrm{L}$ protein solution and $0.5 \mu \mathrm{L}$ of precipitant solution, 
and were equilibrated over a reservoir volume of $70 \mu \mathrm{L}$ at $20^{\circ} \mathrm{C}$. After a few days, crystals appeared in several conditions.

Two conditions were further optimized as described below. Binary crystals composed of $\mathrm{Ftn}^{(\mathrm{pos})}$ and $\mathrm{Ftn}^{(\mathrm{neg})}$ were grown using the hanging-drop vapor-diffusion method in a 24-well manual plate setup. Purified $\mathrm{Ftn}^{(\mathrm{pos})}$ in $50 \mathrm{mM}$ Tris, $\mathrm{pH} 7.5,1 \mathrm{M} \mathrm{NaCl}$ and $\mathrm{Ftn}^{(\mathrm{neg})}$ in $50 \mathrm{mM}$ Tris, $\mathrm{pH} 7.5,0.3 \mathrm{M} \mathrm{NaCl}$ were concentrated to $4 \mathrm{mg} / \mathrm{mL}$ respectively $8 \mathrm{mg} / \mathrm{mL}$. Drops were prepared on siliconized glass cover slides (Jena Bioscience) by mixing $2 \mu \mathrm{L}$ of reservoir solution (condition 1: 100-200 mM magnesium formate; condition 2: 100-200 mM magnesium acetate, $100 \mathrm{mM}$ Tris, $\mathrm{pH} 8.5$ ) with $1 \mu \mathrm{L} \mathrm{Ftn}^{\text {(pos) }}$ solution and $1 \mu \mathrm{L} \mathrm{Ftn}^{\text {(neg) }}$ solution, and equilibrated against the reservoir solution $(500 \mu \mathrm{L})$ at $20^{\circ} \mathrm{C}$. First crystals were visible after $2 \mathrm{~h}$ and crystals with $100 \mu \mathrm{m}$ edge length or larger formed in less than one day (Fig. 2B and Fig. S3). The crystals had a morphology similar to the octahedral habit observed for wild type ferritin. ${ }^{[6]}$

In order to test if both protein variants are mandatory for crystal formation, control experiments were performed with crystallization trials containing only one protein variant. Either Ftn ${ }^{(\mathrm{pos})}$ solution or Ftn ${ }^{(\mathrm{neg})}$ solution was substituted in the crystallization drop with the same volume of $50 \mathrm{mM}$ Tris, $\mathrm{pH} 7.5,1 \mathrm{M} \mathrm{NaCl}$ or $50 \mathrm{mM}$ Tris, $\mathrm{pH}$ 7.5, $0.3 \mathrm{M} \mathrm{NaCl}$, respectively. After 7 days, the drops were checked for crystal growth. However, no crystals could be observed in both conditions. To rule out that the decrease in total protein concentration in the control experiments was not the cause for the absence of crystal formation, drops with both variants present but only at half the initial protein concentration $(2 \mathrm{mg} / \mathrm{mL})$ were prepared. In these trials, crystals of similar size and habit as in the regular binary crystal growth conditions formed, albeit in smaller number.

Structure Determination and refinement. For data collection, crystals were soaked for $120 \mathrm{~s}$ in cryo buffer containing $25 \%$ glycerol and the respective reservoir solution, and vitrified in liquid nitrogen.

Diffraction data were collected at $100 \mathrm{~K}$ on the PX-III (X06DA) beamline at the Swiss Light Source, Villigen, Switzerland (support by the beamline staff at X06DA is gratefully acknowledged). Data were processed and scaled with $\operatorname{XDS}^{[7]}$. The structures were solved with Phaser ${ }^{[8]}$ using PDB ID 2CEI. Refinement was carried out 
with Refmac ${ }^{[9]}$ within the CCP4 suite. ${ }^{[10]}$ Mutations for Ftn $^{(\text {pos })}$ and Ftn ${ }^{(\text {neg) }}$ were introduced with Coot. ${ }^{[11]}$ The models were improved by iterative rounds of refinement and manual rebuilding. Engineered and native side chains were modeled with full occupancy. Thermal displacement factors for atoms of mutated side chains are similar to the ones for native solvent-exposed side chains.

Two crystal structures were determined: a binary structure composed of $\mathrm{Ftn}^{(\mathrm{pos})}$ and $\mathrm{Ftn}^{(\mathrm{neg})}$ containers, obtained from magnesium formate salt crystallization condition (condition 1, see above) and a binary structure obtained from magnesium acetate salt crystallization condition (condition 2 , see above).

Metal ions were placed based on electron density, other atoms in the coordination sphere and anomalous electron density maps, which were generated from data collected at $1.00 \AA$ and $1.77 \AA$ (Tab. S1). $\mathrm{Fe}^{3+}$ ions were placed at the ferroxidase site and at the fourfold channel. $\mathrm{Mg}^{2+}$ ions were placed in the threefold channel, coordinated by six water molecules. Metal ions are absent at the contact interfaces between $\mathrm{Ftn}^{(\mathrm{pos})} / \mathrm{Ftn}^{(\mathrm{neg})}$ or $\mathrm{Ftn}^{(\mathrm{pos})} / \mathrm{Ftn}^{(\mathrm{pos})}$ or $\mathrm{Ftn}^{(\mathrm{neg})} / \mathrm{Ftn}^{(\mathrm{neg})}$.

Data collection statistics and refinement details are shown in Tab. S1. Model validation was carried out with the Molprobity server. ${ }^{[12]}$ For both structures, more than $98 \%$ of the residues are within the most favored regions of the Ramachandran plot and no outliers are observed (Tab. S1). Molprobity scores: 0.82 (structure from $\mathrm{Mg}$ formate) and 1.03 ( $\mathrm{Mg}$ acetate) indicating that these structures are in the $99^{\text {th }}$ percentile for $\mathrm{N}=837,1.80 \AA \pm 0.25 \AA$. The structures described in this manuscript have been deposited with the PDB with accession codes 5JKL and 5JKM. The program PyMOL (DeLano Scientific LLC) was employed for figure preparation. Electrostatic potentials were visualized with the APBS plugin ${ }^{[13]}$ on the solventexposed surface (Fig. 2A).

Electron density maps for introduced mutations (omit maps). To verify that both variants, and thus the mutations, are present at distinct position within the lattice, an omit map (2Fo-Fc) and a difference electron density map (Fo-Fc) were calculated without the side chain atoms (deleted after $\mathrm{C}_{\text {beta }}$ ) of the residues in question. The program CC4Pmg was used for preparation of Fig. S4. ${ }^{[14]}$ The maps are shown for two residues of Ftn ${ }^{(\mathrm{pos})}$, namely mutation Asn25Arg and Cys90Lys, and two residues of Ftn $^{\text {(neg) }}$, Asn25 (no mutation) and mutation Cys90Glu. The omit map (blue, 
contoured at $1 \sigma$ ) and the difference electron density map (green, contoured at a high level of $5 \sigma$ ) clearly show that the introduced side chains (Arg25, Lys90) are present for $\mathrm{Ftn}^{(\mathrm{pos})}$. For $\mathrm{Ftn}^{(\mathrm{neg})}$, position 25 was not mutated and the electron density maps clearly show that at this position the native residue Asn is present, in contrast to the mutation to Arg for Ftn ${ }^{\text {(pos) }}$. Moreover, electron density maps for residue 90 show that at this position Ftn $^{\text {(neg) }}$ contains the mutation to Glu. The electron density maps show the ordered binary composition of the crystals.

Structural analysis. The difference between the binary structure from the magnesium formate and magnesium acetate crystallization conditions is only marginal (main chain atoms RMSD $0.078 \AA$ ). Because of higher data and model quality indicators (Table S1), the binary structure from the magnesium formate condition was used for further analysis of the contact interfaces between containers, supported by the PISA server. ${ }^{[15]}$ The interaction between containers always takes place close to the twofold symmetry axis of the ferritin container (dimer interface). For each type of contact, a different set of residues is recruited to form hydrogen bonds and salt bridges with the contact partner. Hydrogen bonds are formed either directly or with additional water molecules involved. Interestingly, for contacts between $\mathrm{Ftn}^{(\mathrm{pos})}$ and $\mathrm{Ftn}^{(\mathrm{neg})}$, the major fraction of residues involved is composed of native, unmutated side chains from the parent protein. Newly introduced positively $\left(\mathrm{Ftn}^{(\mathrm{pos})}\right)$ or negatively charged residues $\left(\mathrm{Ftn}^{(\mathrm{neg})}\right)$ are only found in a small number of contacts (Glu18 and Lys18, colored red in Fig. S5A). In contrast to contacts in wild-type ferritin crystal structures, some contacts between $\mathrm{Ftn}^{(\mathrm{pos})}$ and $\mathrm{Ftn}^{(\mathrm{neg})}$ include hydrogen bonds distant to the main contact interface (Glu18, chain H $\rightarrow$ Lys119, chain A, Fig. S5A). There is a second $\mathrm{Ftn}^{(\mathrm{pos})}$ and $\mathrm{Ftn}^{(\mathrm{neg})}$ interface, not related by symmetry to the first one, which contains mostly the same hydrogen bonds shown in Fig. S5A, but a few side chains make slightly different contacts, underscoring the plasticity of the interaction surface.

Contacts between two $\mathrm{Ftn}^{(\mathrm{pos})}$ containers involve hydrogen bonds, for example between the newly introduced Lys90 (chain D) and symmetry equivalents of Asp84, chain $\mathrm{C}$ and Gln86, chain D. In native ferritin crystal structures these Gln86 and Asp84 residues, along with their symmetry equivalents, are the residues that mediate crystal contacts between ferritin containers in the crystal lattice via metal ions, e.g. two $\mathrm{Zn}^{2+}$ ions in PDB ID 2CEI. ${ }^{[16]}$ However, very interestingly in the present structure these residues interact in place of metal cations with the newly introduced cationic 
residue Lys90 (Fig. S5B). Contacts between two $\mathrm{Ftn}^{(\mathrm{neg})}$ containers involve hydrogen bonds, mostly mediated by water molecules (Fig. S5C). In addition, there is a hydrogen bond between symmetry-related residues Gln83 (chain J). The formation of the tetragonal structure can be rationalized by the high plasticity of the coordination interface, which is either involved in contacts with oppositely or with like-charged containers.

\section{Synthesis of metal oxide nanoparticles within $\mathrm{Ftn}^{(\mathrm{pos})}$ and Ftn $^{(\mathrm{neg})}$}

Iron oxide: Buffers (50 mM Tris, $\mathrm{pH} 7.5 ; 0.3 \mathrm{M} \mathrm{NaCl}$ for $\mathrm{Ftn}^{(\text {neg) }}, 1 \mathrm{M} \mathrm{NaCl}$ for Ftn ${ }^{\text {(pos) }}$, $\mathrm{H}_{2} \mathrm{O}$ milliQ and $\mathrm{H}_{2} \mathrm{O}_{2}$ solutions were depleted of $\mathrm{O}_{2}$ by bubbling $\mathrm{N}_{2}$ through the solutions for at least $15 \mathrm{~min}$. Buffer was preheated in a $65^{\circ} \mathrm{C}$ oil bath for $20 \mathrm{~min}$ in oxygen-free atmosphere in a two-neck round-bottom flask $(25 \mathrm{~mL})$ with constant stirring. $4 \mathrm{mg}$ of either $\mathrm{Ftn}^{\text {(pos) }}$ or Ftn $^{\text {(neg) }}$ in buffer were added to a total volume of $10 \mathrm{~mL}$. After $10 \mathrm{~min}, \mathrm{H}_{2} \mathrm{O}_{2}(6 \mathrm{mM})$ and $\left(\mathrm{NH}_{4}\right)_{2} \mathrm{Fe}\left(\mathrm{SO}_{4}\right)_{2}(18 \mathrm{mM})$ dissolved in deaerated $\mathrm{H}_{2} \mathrm{O}$ milliQ were added in equal volumes using Perfusor compact $\mathrm{S}$ syringe pumps (B. Braun). Up to $5000 \mathrm{Fe}(\mathrm{II})$ ions were injected per ferritin cage at a flow rate of 100 ions per minute per ferritin cage. Once the addition was complete, the solution was kept in the water bath for another $15 \mathrm{~min}$, and finally $400 \mu \mathrm{L}$ sodium citrate (300 $\mathrm{mM}$ stock solution) were added to chelate residual iron ions. After additional $15 \mathrm{~min}$ at $65^{\circ} \mathrm{C}$, the solution was centrifuged for $10 \mathrm{~min}$ at $14,000 \mathrm{~g}$ and $4{ }^{\circ} \mathrm{C}$. The supernatant was rebuffered $5 \mathrm{x}$ with buffer with an Amicon Ultra-15 centrifugal filter unit (30 kDa MWCO) to remove excess reagents and injected on a HiLoad 16/600 Superdex 200 PG gel filtration column.

Iron loading efficiency was monitored by comparing the $350 \mathrm{~nm}$ absorption with the $280 \mathrm{~nm}$ absorption in the monomeric ferritin fractions (Fig. S6A). Absorbance of individual fractions was measured with a NanoDrop 2000 spectrophotometer. Nanoparticle formation was analyzed by transmission electron microscopy of stained and unstained protein samples (Fig. S7A and S8A, Tab. S2). Concentrations of nanoparticle loaded proteins were estimated with the Bradford method.

Cobalt oxide: Synthesis of cobalt oxide nanoparticles was similar to iron oxide nanoparticle synthesis with some modifications. In detail, instead of Tris buffer a HEPES buffer was used (100 mM HEPES, 0.2 M NaCl, $\mathrm{pH} 8.3$ ). Amount of protein was $15 \mathrm{mg}$ in a total volume of $20 \mathrm{~mL}$ (50 mL two-neck round-bottom flask). 
$\left(\mathrm{NH}_{4}\right)_{2} \mathrm{Co}\left(\mathrm{SO}_{4}\right)_{2}(30 \mathrm{mM})$ and $\mathrm{H}_{2} \mathrm{O}_{2}(10 \mathrm{mM})$ were added at a rate of $45 \mathrm{Co}$ (II) ions per minute per ferritin cage with a total of 2250 ions per cage. $1.5 \mathrm{~mL}$ sodium citrate $(300 \mathrm{mM})$ was added at the end of the reaction. Before purification by gel filtration the sample was centrifuged several times for $10 \mathrm{~min}$ at $20,000 \mathrm{~g}$ and $4{ }^{\circ} \mathrm{C}$ to remove small aggregates.

Cobalt loading efficiency was monitored at $400 \mathrm{~nm}$ (Fig. S6B) and samples were characterized by TEM as for iron-loaded samples (Fig. S7B and S8B, Tab. S2).

Cerium oxide: Synthesis of cerium oxide nanoparticles was done under similar conditions and in the same buffer as for the synthesis of iron oxide nanoparticles. Amount of protein was $15 \mathrm{mg}$ in a total volume of $20 \mathrm{~mL}$. $\mathrm{CeCl}_{3}(30 \mathrm{mM})$ and $\mathrm{H}_{2} \mathrm{O}_{2}$ $(15 \mathrm{mM})$ were added at a rate of $37 \mathrm{Ce}(\mathrm{III})$ ions per minute per ferritin cage with a total of 2225 ions per cage. Instead of sodium citrate $1.2 \mathrm{~mL}$ EDTA (500 mM stock solution) were added at the end of the reaction. The sample was centrifuged several times as for cobalt oxide samples before gel filtration.

Cerium loading efficiency was monitored at $350 \mathrm{~nm}$ (Fig. S6C) and samples were characterized as for iron-loaded samples (Fig. S7C and S8C, Tab. S2).

\section{Sucrose gradient centrifugation of nanoparticle-loaded samples}

To separate empty or sparsely loaded capsids from nanoparticle-loaded capsids, sucrose gradient centrifugation was performed. $2 \mathrm{~mL}$ of loaded samples were layered on top of a step-wise sucrose gradient $(20 \%, 40 \%$, and $70 \%)$ in $20 \mathrm{~mL}$ ultracentrifugation tubes. Samples were centrifuged with an Optima XPN-80 ultracentrifuge (Beckman Coulter) for $3 \mathrm{~h}$ at 193,000 $\mathrm{g}$ and $4{ }^{\circ} \mathrm{C}$. To recover the nanoparticle-loaded capsids, $1 \mathrm{~mL}$ fractions were separated using a pipette, starting from the top. Nanoparticle containing samples were washed from sucrose using Amicon Ultra-15 centrifugal filter units (30 kDa MWCO).

First trials with iron-loaded samples showed that after the synthesis nearly all protein containers were loaded and therefore sucrose gradient centrifugation was only performed for cobalt and cerium oxide loaded samples.

\section{Transmission electron microscopy, electron diffraction}

Concentrations of $0.1-0.5 \mathrm{mg} / \mathrm{mL}$ protein were used. Copper grids, $400 \mathrm{mesh}$, covered with Formvar and carbon (Ted Pella, 01814-F) were incubated face down on a $15 \mu \mathrm{L}$ 
droplet of sample. The grids were then washed $3 \mathrm{x}$ in $\mathrm{H}_{2} \mathrm{O}$ milliQ, followed by 1 wash and 1 incubation ( $30 \mathrm{~s}$ ) on $2 \%$ uranyl acetate drops. Uranyl acetate incubations were omitted for unstained samples. All analyses were carried out with a Zeiss Libra 200 FE transmission electron microscope, with energy filters and operated at $200 \mathrm{kV}$. Images were analyzed using the ImageJ software. ${ }^{[17]}$ For electron diffraction, diffraction patterns were collected from unstained samples using a condenser aperture (37.5 $\mu \mathrm{m}$ width) and a camera length of $480 \mathrm{~mm}$. A commercial evaporated gold from Plano $\mathrm{GmbH}$ was used for calibrating the system prior to the experiment.

d-spacings for cobalt and cerium oxide nanoparticles were determined from the diffraction patterns (Fig. S9 and S10). The iron oxide samples did not show a clear diffraction pattern, similarly as observed for synthesis of iron oxide within a different ferritin variant, ${ }^{[18]}$ where it is assumed that the iron oxide phase is an amorphous or poorly crystalline ferrihydrite $\left(\mathrm{FeO}_{\mathrm{x}}\right)$. The cobalt oxide nanoparticles can clearly be identified as $\mathrm{Co}_{3} \mathrm{O}_{4}$ (see Tab. S3). The cerium oxide nanoparticles can clearly be identified as $\mathrm{CeO}_{2}$ (see Tab. S4).

\section{Binary nanoparticle superlattices}

From sixteen possible crystal combinations (empty, $\mathrm{FeO}_{\mathrm{x}}, \mathrm{Co}_{3} \mathrm{O}_{4}$ and $\mathrm{CeO}_{2}$ inside either $\mathrm{Ftn}^{(\mathrm{pos})}$ or $\mathrm{Ftn}^{(\mathrm{neg})}$ ), eight combinations (see Tab. S5) were selected and crystals with the respective cargo loading were produced as described above for crystals of empty $\mathrm{Ftn}^{(\mathrm{pos})}$ or $\mathrm{Ftn}^{(\mathrm{neg})}$. Crystals for empty protein containers are shown in Fig. 2B and Fig. S3). Crystals for nanoparticle-loaded containers are shown in Fig. 3, Fig S11 and S12.

For protein-nanoparticle crystals, we often observed a shift to an elongated dodecahedral habit in contrast to the more octahedral morphology of empty crystals.

\section{Optical microscopy}

Samples were directly imaged in manual plates with the hanging-drop setup without removing the cover slide using a Zeiss Stemi SV 11 stereomicroscope equipped with a Canon EON Rebel T1i camera. For pictures of single crystals the cover slide with the hanging-drop was removed and carefully placed on a microscope slide. Samples were imaged with a Zeiss Axioplan 2 microscope equipped with a FireWire 400 color 
industrial camera (Imaging Source). A ruler at the sample position was used to determine the scale for the images.

\section{Crystal fixation}

Crystals were fixated in situ in the hanging drop of the crystallization setup. The cover slide with the crystals in the crystallization drop was briefly removed to add $10 \mu \mathrm{L}$ of $25 \%$ glutaraldehyde to the reservoir solution (final concentration $0.5 \%$ ), followed by mixing of the reservoir solution with the pipette tip. The cover slide with the crystallization drop was put back on the reservoir and the crystallization plate was incubated up to $48 \mathrm{~h}$. Glutaraldehyde diffuses slowly into the crystallization drop and gently crosslinks the crystals within the drop. ${ }^{[19]}$

\section{Scanning electron microscopy (SEM), energy dispersive X-ray spectroscopy (EDX)}

Fixated crystals were washed three times in milliQ water and transferred to a carbon foil on a SEM stub. Crystals were imaged with a high-resolution field emission scanning electron microscope (FE-SEM, LEO/ZEISS Supra 35 VP, Oberkochen, Germany) under reduced pressure (VP mode, $10^{-4} \mathrm{mbar}$ ). Energy dispersive electron X-ray spectroscopy was carried out with an EDX detector (Oxford, Germany, with SiLi crystal, $133 \mathrm{eV}, 10 \mathrm{~mm}^{2}$ ). EDX maps were prepared with the INCA Energy 200 software.

\section{Small angle $\mathrm{X}$-ray scattering (SAXS)}

SAXS data were obtained from fixated crystals in mother liquor, transferred to a borosilicate glass capillary (Hilgenberg $\mathrm{GmbH}$, Germany). The capillary was mounted into a capillary holder that is rotated around its vertical axis by an electric motor (Sol Expert) with 12.6 rotations per minute to ensure that ensemble diffraction from the sample was recorded rather than Bragg peaks from only a few crystals that are by serendipity oriented in diffraction condition. By recording the diffraction rings, the reflection intensities can be reliably quantified and put in relation to each other.

SAXS data were recorded with a S-Max3000 system equipped with a Rigaku MicroMax-002+X-ray microfocus generator $(\mathrm{Cu} \mathrm{K \alpha}$ radiation, $\lambda=1.54 \AA)$ in a $q$ range from $0.004-0.22 \AA^{-1}$ at room temperature. Sample-to-detector distance was $2.59 \mathrm{~m}$, and a silver behenate standard sample was used for calibration of the length 
of the scattering vector $q$. Data were analyzed with SAXSGUI (Rigaku Innovative Technologies, Inc. and JJ X-Ray Systems ApS). One-dimensional SAXS data were obtained by azimuthally averaging the $2 \mathrm{D}$ scattering data. The magnitude of the scattering vector $q$ is given by $q=4 \pi \sin \theta / \lambda$, where $2 \theta$ is the scattering angle.

Unit cell parameters for each data set were determined using the scattering vector $q$ for reflections (100) and (001) (for samples with both containers empty: reflections (110) and (002)). First, the relation between the scattering angle and scattering vector $q=4 \pi \sin \theta / \lambda$ and the quadratic Bragg equation for the tetragonal crystal system were combined to give eq. 1 :

$$
q_{h k l}=\frac{2 \pi}{a} \sqrt{h^{2}+k^{2}+\left(\frac{a}{c}\right)^{2} l^{2}}
$$

For reflections (100) and (001), cell parameters $c$ and $a$ can be determined using:

$$
\begin{aligned}
& a=\frac{2 \pi}{q_{100}} \\
& c=\frac{2 \pi}{q_{001}}
\end{aligned}
$$

The $q$ value for reflection (101) was calculated using the derived cell parameters

$$
q_{101}=\frac{2 \pi}{a} \sqrt{1+\left(\frac{a}{c}\right)^{2}}
$$

to be compared with the experimental value, see columns 2 and 4 in Tab. S6 for reflection (101).

Tab. S6 shows that the cell parameters for all samples are very similar (mean value is $a=130.4 \pm 0.5 \AA, c=178.1 \pm 0.5 \AA$ ). For samples with empty containers before and after fixation (Fig. S14) similar cell parameters are observed as well (Tab. S6). The deviation between $q_{101}$ obtained from the experiment and $q_{101}$ calculated from cell parameters $a$ and $c$ is below $0.3 \%$ for all samples.

The shrinkage in the cell parameters obtained for the X-ray crystal structures (Tab. S1) compared to the cell parameters for SAXS data can be readily rationalized with the decreased temperature during single crystal data collection (100 K vs. room temperature for SAXS). 
Unit cell parameters from SAXS experiments were used to simulate diffraction patterns with PowderCell (Federal Institute for Materials Research and Testing, Germany). In binary crystals of Ftn ${ }^{(\mathrm{pos})}$ and $\mathrm{Ftn}^{(\mathrm{neg})}$ with two types of nanoparticles, the nanoparticles form a primitive tetragonal lattice (space group $P 4 / \mathrm{mmm}$ ). In binary crystals with the same type of nanoparticles in both containers, the nanoparticles form a tetragonal body-centered superlattice (space group $14 / \mathrm{mmm}$ ). For samples with differently loaded protein containers (either two different types of nanoparticles, or one container with nanoparticles, one empty, or containers with a different loading degree), in PowderCell appropriate element types were selected to match the intensity ratio between peaks $(001) /(100)$ and peak (101). The simulated diffraction patterns were plotted together with the experimental data in Origin (OriginLab Corporation). The simulated diffraction patterns match well to the experimental data (Fig. 4, Fig. S14, Fig. S15) with regard to the peak positions. However, the intensity patterns are not always reproduced, which can be attributed to several factors. Although the samples were rotated during data collection, several strong Bragg spots appear, which potentially bias the intensity of some diffraction rings. Moreover, the program used to simulate the SAXS diffraction patterns was originally developed for atomic lattices. Therefore, although the peak positions are closely matched, it might not simulate appropriate intensities for nanoparticles superstructures, which was also observed in other studies. $^{[20]}$

The analysis of the SAXS data shows that for mixed superlattice structures (e.g. Fig. $4 \mathrm{C}, \mathrm{CeO}_{2}$ with $\mathrm{Co}_{3} \mathrm{O}_{4}$ ) or for superlattices with only one protein container filled with nanoparticles (e.g. Fig. 4A and B), the nanoparticles form a primitive tetragonal lattices (space group $P 4 / \mathrm{mmm}$ ) by an ordered assembly of the oppositely charged protein containers. In contrast, a random arrangement of two types of nanoparticles would result in having the average electron density of the possible nanoparticles (e.g. cobalt and cerium oxide) for each lattice position. This would correspond to a bodycentered unit cell in space group $I 4 / \mathrm{mmm}$. This space group has a number of reflections that are not observed in the diffraction pattern (systematic absences for peaks with $\mathrm{h}+\mathrm{k}+\mathrm{l}=$ odd sum), for example the two peaks 001 and 100 , preceding the main peak 101. However, these two peaks are present in our SAXS data, which shows that the nanoparticles form an ordered binary arrangement, corresponding to a 
primitive cell setting in space group $P 4 / \mathrm{mmm}$ with distinct lattice positions, further underscoring the results from single crystal X-ray diffraction (e.g. Fig. S4).

On the other hand, when both nanoparticles are from the same type, the nanoparticles form a tetragonal body-centered superlattice (space group $I 4 / \mathrm{mmm}$ ). In this space group, a number of diffraction peaks are expected to be systematically absent (as discussed above). This can be observed for SAXS data of unloaded containers (crystals from Fig. 2B), where both empty containers Ftn $^{(\text {pos) }}$ and Ftn ${ }^{(\text {neg })}$ scatter in an almost identical manner (Fig. S14), and peaks (001) and (100) are absent. For samples with the same nanoparticle type in both containers (Fig. S15B and C), peaks at (001) and (100) show clearly less intensity compared to Fig. 4C and Fig. S15D, but are not completely absent. This can be rationalized by a different loading degree of the two containers $\mathrm{Ftn}^{(\mathrm{pos})}$ and $\mathrm{Ftn}^{(\mathrm{neg})}$ for Fig. S15B and C. For the crystallization setup, fractions with a high degree of loading were combined after sucrose gradient centrifugation. TEM images (Fig. S7 and S8, Tab. S2) show slightly differently sized nanoparticle cores for the combined fractions for $\mathrm{Ftn}^{(\text {pos })} \mathrm{CeO}_{2}$ and $\mathrm{Ftn}^{(\text {neg })} \mathrm{CeO}_{2}$, and $\mathrm{Ftn}^{\text {(pos) }} \mathrm{FeO}_{\mathrm{x}}$ and $\mathrm{Ftn}^{(\text {neg) }} \mathrm{FeO}_{\mathrm{x}}$, respectively (Tab. S2). These differences give rise to the observed weak peaks in the SAXS diffraction patterns. By selecting only the very bottom fraction from the sucrose gradient centrifugation with highly loaded containers, this difference could be alleviated. Despite difference in loading degree of $\mathrm{Ftn}^{(\mathrm{pos})}$ and $\mathrm{Ftn}{ }^{(\mathrm{neg})}$, the binary NP superlattices show high long-range order since the protein containers with their atomically precise envelope override any imperfections of the NP cargo. 


\section{References}

[1] T. Beck, S. Tetter, M. Künzle, D. Hilvert, Angew. Chem. Int. Ed. 2015, 54, 937-940.

[2] A. Leaver-Fay, M. Tyka, S. M. Lewis, O. F. Lange, J. Thompson, R. Jacak, K. Kaufman, P. D. Renfrew, C. A. Smith, W. Sheffler, et al., Method. Enzymol. 2011, 487, 545-574.

[3] A. E. Miklos, C. Kluwe, B. S. Der, S. Pai, A. Sircar, R. A. Hughes, M. Berrondo, J. Xu, V. Codrea, P. E. Buckley, et al., Chem. Biol. 2012, 19, 449455.

[4] G. MacBeath, P. Kast, BioTechniques 1998, 24, 789-794.

[5] M. M. Bradford, Anal. Biochem. 1976, 72, 248-254.

[6] B. R. Thomas, D. Carter, F. Rosenberger, J. Cryst. Growth 1998, 187, 499510.

[7] W. Kabsch, Acta. Crystallogr. 2010, D66, 125-132.

[8] A. J. McCoy, R. W. Grosse-Kunstleve, P. D. Adams, M. D. Winn, L. C. Storoni, R. J. Read, J. Appl. Cryst. 2007, 40, 658-674.

[9] G. N. Murshudov, P. Skubák, A. A. Lebedev, N. S. Pannu, R. A. Steiner, R. A. Nicholls, M. D. Winn, F. Long, A. A. Vagin, Acta Crystallogr. Section D 2011, 67, 355-367.

[10] M. D. Winn, C. C. Ballard, K. D. Cowtan, E. J. Dodson, P. Emsley, P. R. Evans, R. M. Keegan, E. B. Krissinel, A. G. W. Leslie, A. McCoy, et al., Acta Crystallogr. Section D 2011, 67, 235-242.

[11] P. Emsley, B. Lohkamp, W. G. Scott, K. Cowtan, Acta Crystallogr. Section D 2010, 66, 486-501.

[12] V. B. Chen, W. B. Arendall, J. J. Headd, D. A. Keedy, R. M. Immormino, G. J. Kapral, L. W. Murray, J. S. Richardson, D. C. Richardson, Acta Crystallogr. Section D 2010, 66, 12-21.

[13] N. A. Baker, D. Sept, S. Joseph, M. J. Holst, J. A. McCammon, Proc. Natl. Acad. Sci. U.S.A. 2001, 98, 10037-10041.

[14] S. McNicholas, E. Potterton, K. S. Wilson, M. E. M. Noble, Acta Crystallogr. Section D 2011, 67, 386-394.

[15] E. Krissinel, K. Henrick, J. Mol. Biol. 2007, 372, 774-797.

[16] L. Toussaint, L. Bertrand, L. Hue, R. R. Crichton, J.-P. Declercq, J. Mol. Biol. 2007, 365, 440-452.

[17] C. A. Schneider, W. S. Rasband, K. W. Eliceiri, Nat. Methods 2012, 9, 671675.

[18] M. T. Klem, M. Young, T. Douglas, J. Mater. Chem. 2009, 20, 65-67.

[19] M. Salem, Y. Mauguen, T. Prangé, Acta Crystallogr. Section F 2010, 66, 225228.

[20] C. Zhang, R. J. Macfarlane, K. L. Young, C. H. J. Choi, L. Hao, E. Auyeung, G. Liu, X. Zhou, C. A. Mirkin, Nat. Mater. 2013, 12, 741-746.

[21] I. S. Kotousova, S. M. Polyakov, Kristallografiya 1972, 17, 661-663.

[22] M. Deliens, H. Goethals, Mineral. Mag. 1973, 39, 152-157.

[23] R. G. Delaplane, J. A. Ibers, J. R. Ferraro, J. J. Rush, J. Chem. Phys. 1969, 50, 1920-1927.

[24] C. Artini, M. Pani, M. M. Carnasciali, M. T. Buscaglia, J. R. Plaisier, G. A. Costa, Inorg. Chem. 2015, 54, 4126-4137. 


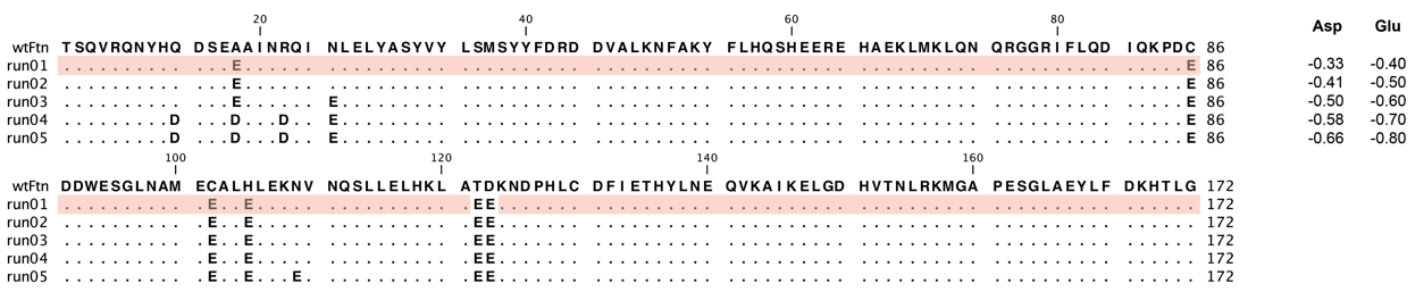

Figure S1. Computational design with Rosetta fixbb module for Ftn ${ }^{(\text {neg })}$. The reference energy weight for Asp and Glu was set to different values for the respective runs (as noted to the right of the sequences). For each run, the sequence with the lowest total Rosetta energy is shown. The sequence for the final design $\mathrm{Ftn}^{(\text {neg) }}$ is highlighted in red. It is based on run01; however, suggestions for mutation close to the three-fold channel (T122E) and for mutation to a similarly charged amino acid (D123E) were not considered. Mutations for variant $\mathrm{Ftn}^{(\text {neg) }}$ are A18E, C90E, C102E, H105E. 

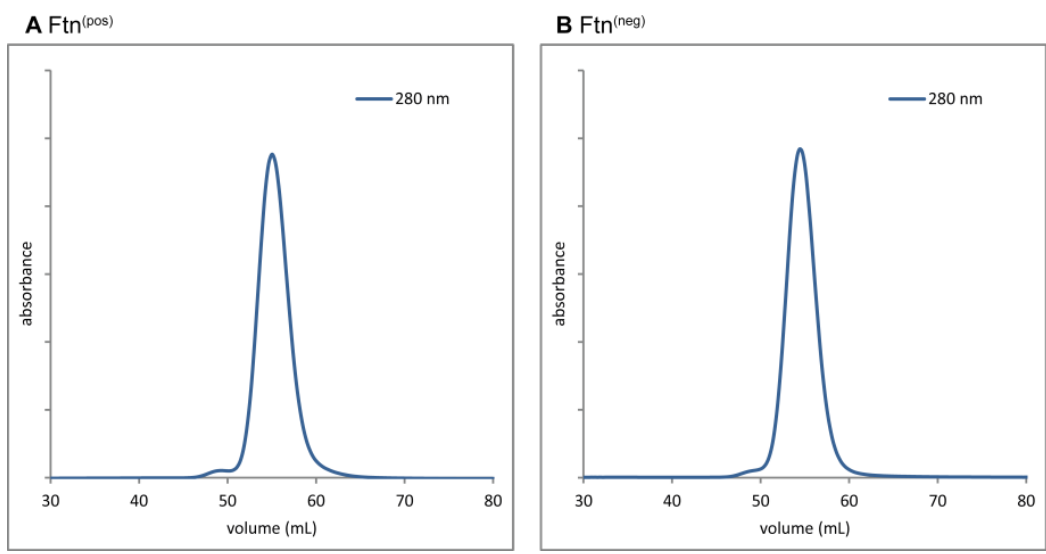

C

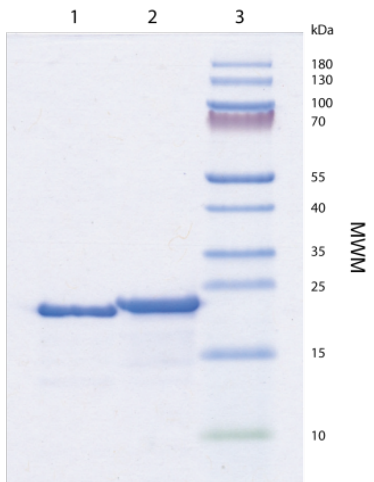

Figure S2. Purification of Ftn ${ }^{\text {(pos) }}$ and Ftn ${ }^{(\text {neg) }}$. (A) Gel filtration chromatogram of

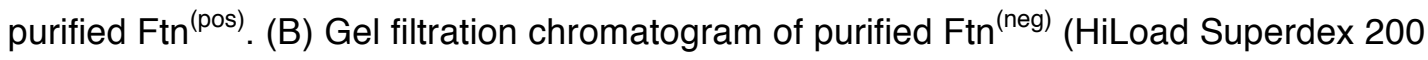
PG column, GE Healthcare). (C) 11\% Tricine-SDS-PAGE. Lane 1: Ftn ${ }^{\text {(pos) }}$; Lane 2: $\mathrm{Ftn}^{(\text {(neg) }}$; Lane 3: Molecular weight marker (PageRuler ${ }^{\mathrm{TM}}$ Prestained Protein Ladder, ThermoScientific). Note that $\mathrm{Ftn}^{\left({ }^{(n e g)}\right.}$ exhibits a small gel shift in comparison with its actual mass $(21196 \mathrm{Da})$ as verified by MALDI-TOF-MS. Ftn ${ }^{\text {(pos) }}(21331 \mathrm{Da})$ runs at its corresponding height. 


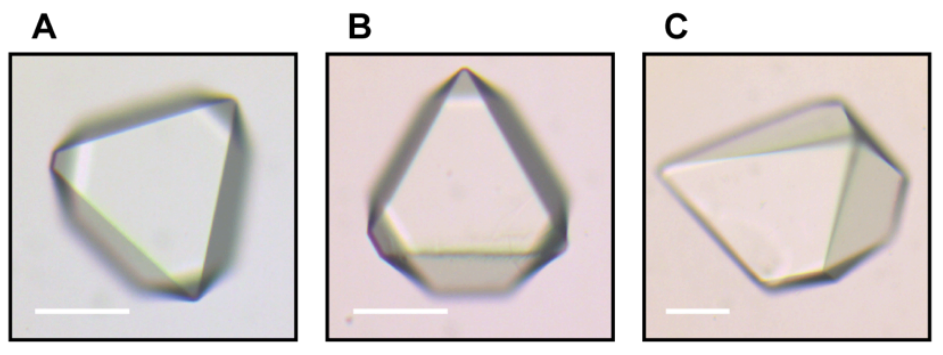

Figure S3. Microscopy images of binary crystals. (A-C) Optical microscopy pictures of representative binary crystals from $\mathrm{Ftn}^{(\mathrm{pos})}$ and $\mathrm{Ftn}^{(\mathrm{neg})}$ without nanoparticle cores. Scale bars are $50 \mu \mathrm{m}$. 
Table S1. Data statistics and refinement details for the binary crystal structures obtained from condition 1 ( $0.19 \mathrm{M}$ magnesium formate, $4 \mathrm{mg} / \mathrm{mL} \mathrm{Ftn}^{\left({ }^{\text {(os) }}\right)}$ and $4 \mathrm{mg} / \mathrm{mL} \mathrm{Ftn}^{(\text {neg) }}$ ) and from condition $2\left(0.20 \mathrm{M}\right.$ magnesium acetate, $100 \mathrm{mM}$ Tris, $\mathrm{pH} 8.5,8 \mathrm{mg} / \mathrm{mL} \mathrm{Ftn}^{\left(\mathrm{pos}^{\circ}\right)}$ and $8 \mathrm{mg} / \mathrm{mL} \mathrm{Ftn}^{(\text {neg })}$.

\section{Data collection}

Wavelength $(\AA)$

Space group

Unit cell dimensions [a, $c(\AA)]$

Resolution range $(\AA)$

Highest resolution shell $(\AA)$

No. of observed reflections

No. of unique reflections ${ }^{a}$

Multiplicity

Completeness (\%)

$<|/ \sigma|>$

$\mathrm{R}_{\text {merge }}(\%)$

$\mathrm{R}_{\text {meas }}(\%)$

Wilson B-factor

\section{Mg formate}

Mg acetate

$\begin{array}{rrr}1.00 & 1.00 & 1.77 \\ P 4 & P 4 & P 4 \\ 126.62, & 126.84, & 127.21 \\ 174.86 & 175.02 & 175,93 \\ 48.85-1.80 & 47.60-1.80 & 49.12-2.24 \\ 1.90-1.80 & 1.90-1.80 & 2.34-2.24 \\ 1,130,658 & 1,441,432 & 1,192,645 \\ 252,223 & 253,942 & 133,490 \\ (12,565) & (12,649) & \\ 4.46(4.41) & 5.65(5.16) & 8.92(7.87) \\ 99.4(100) & 99.6(98.2) & 99.9(99.1) \\ 22.9(5.16) & 19.5(3.71) & 20.5(3.47) \\ 4.52(25.0) & 6.28(38.1) & 10.5(47.0) \\ 5.13(28.4) & 6.93(42.3) & 11.4(50.3) \\ 18.0 & 18.8 & \end{array}$

\section{Refinement}

$\mathrm{R}_{\text {work }}(\%)$

14.7

15.9

$\mathrm{R}_{\text {free }}(\%)$

17.6

19.1

No. atoms

18530

18682

macromolecules

17124

17124

ions / glycerol

water

58

42

1348

1516

$B$-factor $\left(\AA^{2}\right)$

19.2

20.4

macromolecules

18.7

19.9

ions / glycerol

29.0

31.7

solvent

25.4

25.8

R.m.s. deviations

bond lengths ( $\AA$ )

0.020

0.019

bond angles (deg)

1.82

1.74

Ramachandran statistics (\%)

favored

98.7

98.6

outliers

Molprobity score

PDB ID

0.82

1.03

$5 \mathrm{JKL}$

5JKM

${ }^{a}$ Value in parentheses indicates number of reflections used for $R_{\text {free }}$ calculation. 


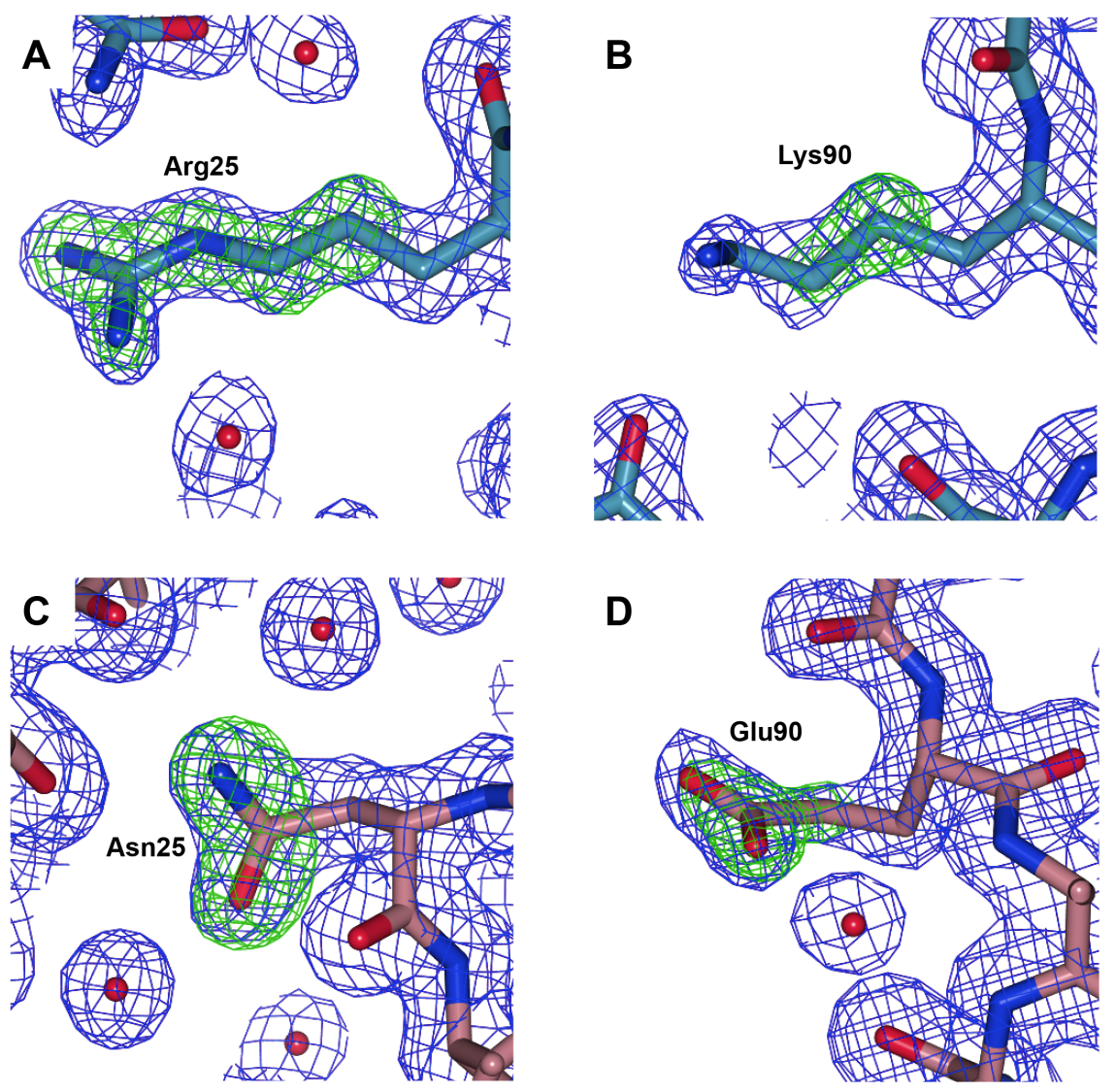

Figure S4. Electron density omit maps for the mutations of the $\mathrm{Ftn}^{(\mathrm{pos})}$ and $\mathrm{Ftn}^{(\mathrm{neg})}$ variants in the binary crystal structure. Electron density $\left(2 F_{0}-F_{c}\right.$ omit map, blue $)$ and difference electron density $\left(F_{0}-F_{c}\right.$, green) maps are shown for two positions, residue 25 ( $A$ and $C$ ) and residue $90(B$ and $D)$ for both variants. For $F t^{(\text {pos })}$, panels $(A)$ with Arg25 (chain $F$ ) and $(B)$ with Lys90 (chain $D$ ) clearly show electron density for the mutations and thus confirm the presence of $\mathrm{Ftn}^{(\text {pos })}$ in the crystal structure. Similarly, for Ftn ${ }^{(\text {neg) }}$, panels (C) with Asn25 (chain I), which was not mutated for Ftn ${ }^{(\text {neg) }}$, and (D) with Glu90 (chain $\mathrm{G}$ ) clearly show electron density for the side chain atoms and thus confirm the presence of $\mathrm{Ftn}^{(\text {neg) }}$ in the crystals structure, together showing that the crystal is composed of both variants. $2 F_{0}-F_{c}$ map (blue): $1.0 \sigma, F_{0}-F_{c}$ map (green): $5 \sigma$. Maps were calculated without the side chain atoms of the labeled residues. 

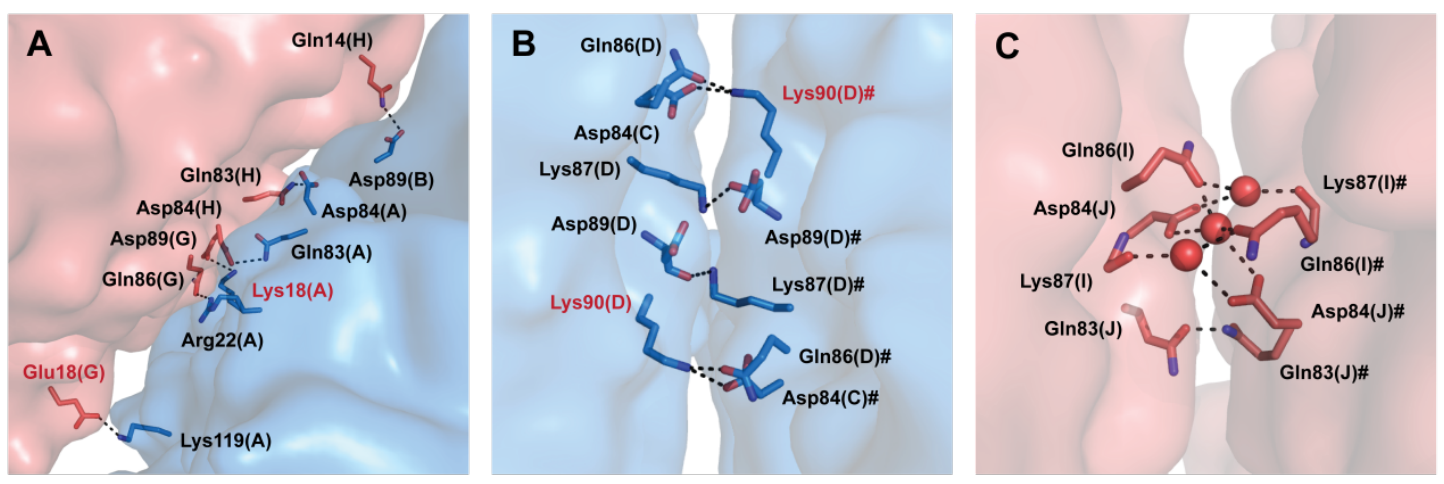

Figure S5. Contacts between protein containers in the binary crystal structures.

Direct hydrogen bonds are shown as dotted lines. For clarity reasons, hydrogen bonds involving water molecules are omitted for panel A and B. (A) Interface between $\mathrm{Ftn}^{\text {(pos) }}$ and $\mathrm{Ftn}^{(\mathrm{neg})}$. (B) Interface between $\mathrm{Ftn}^{(\mathrm{pos})}$ and $\mathrm{Ftn}^{(\mathrm{pos})}$. Containers are related by a twofold symmetry axis in the crystal unit cell. Symmetry-equivalent residues are denoted with \#. Lys87 interacts with the carbonyl O of Asp89, chain D. (C) Interface between $\mathrm{Ftn}^{\left({ }^{(n e g)}\right.}$ and $\mathrm{Ftn}^{(\text {neg) }}$. Containers are related by a twofold symmetry axis in the crystal unit cell.

Symmetry-equivalent residues are denoted with \#. Water molecules are shown as red spheres. Hydrogen bonding of water molecules also includes a bond to the carbonyl $O$ of Lys87 (side chain not shown for clarity reasons). Residue labels include the chain letter in parentheses, with mutated residues highlighted in red. 

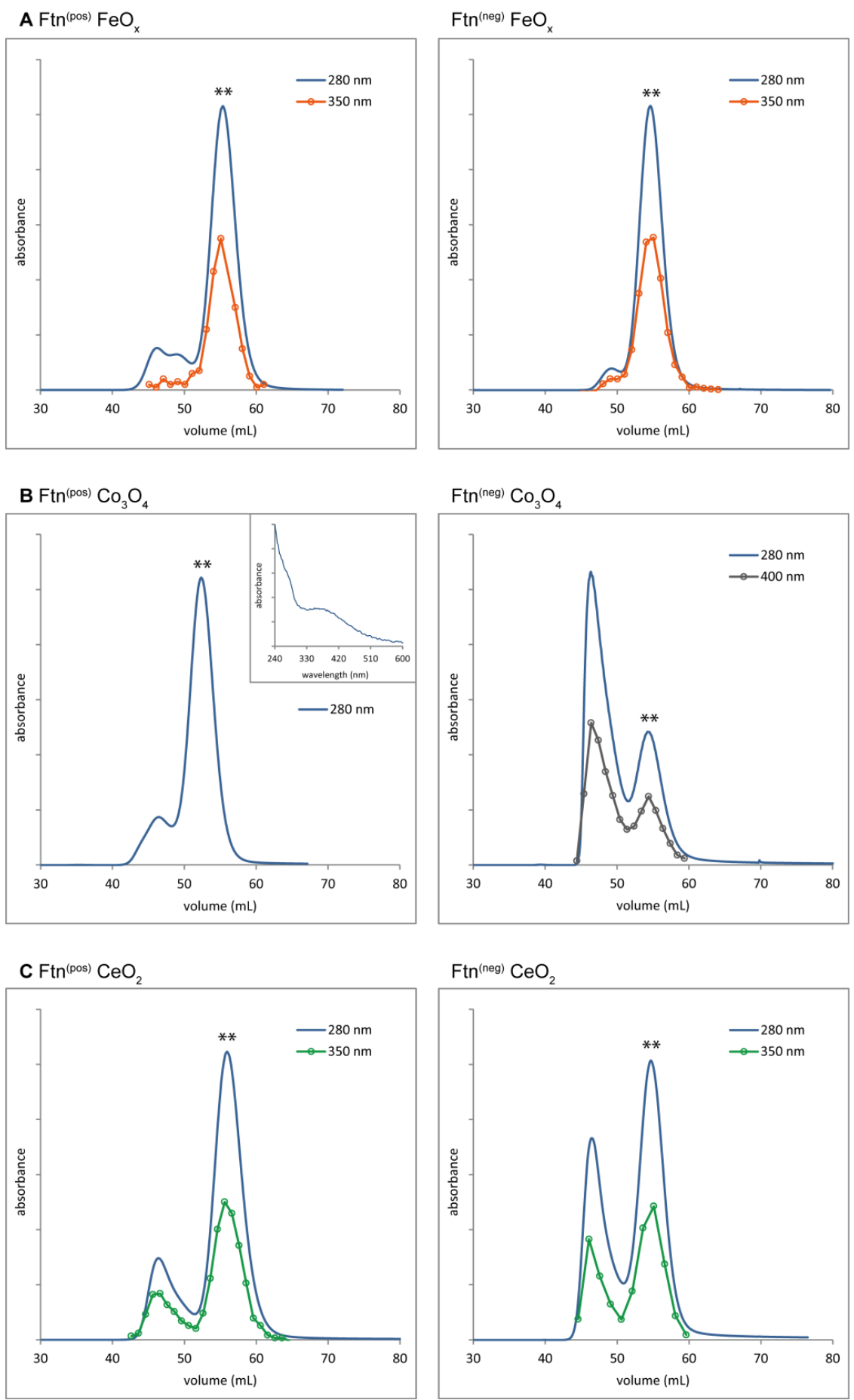

Figure S6. Metal oxide nanoparticle synthesis in $\mathrm{Ftn}^{(\mathrm{pos})}$ and $\mathrm{Ftn}^{(\mathrm{neg})}$. Gel filtration

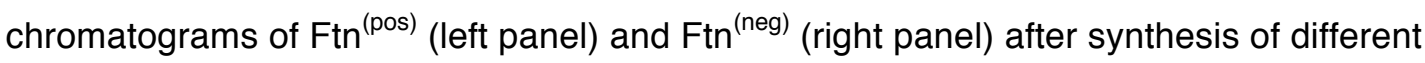
metal oxide nanoparticles. Monomeric protein container fractions are marked with asterisks $\left({ }^{* \star}\right)$. The prepeak corresponds to higher aggregates of the protein containers. The metal oxide minerals coelute with the protein container. (A) Iron oxide nanoparticles; (B) cobalt oxide nanoparticles; Insert: absorption spectrum of $\left({ }^{* *}\right)$-fractions; (C) cerium oxide nanoparticles. 
A Ftn $^{\text {(pos) }} \mathrm{FeO}_{x}$
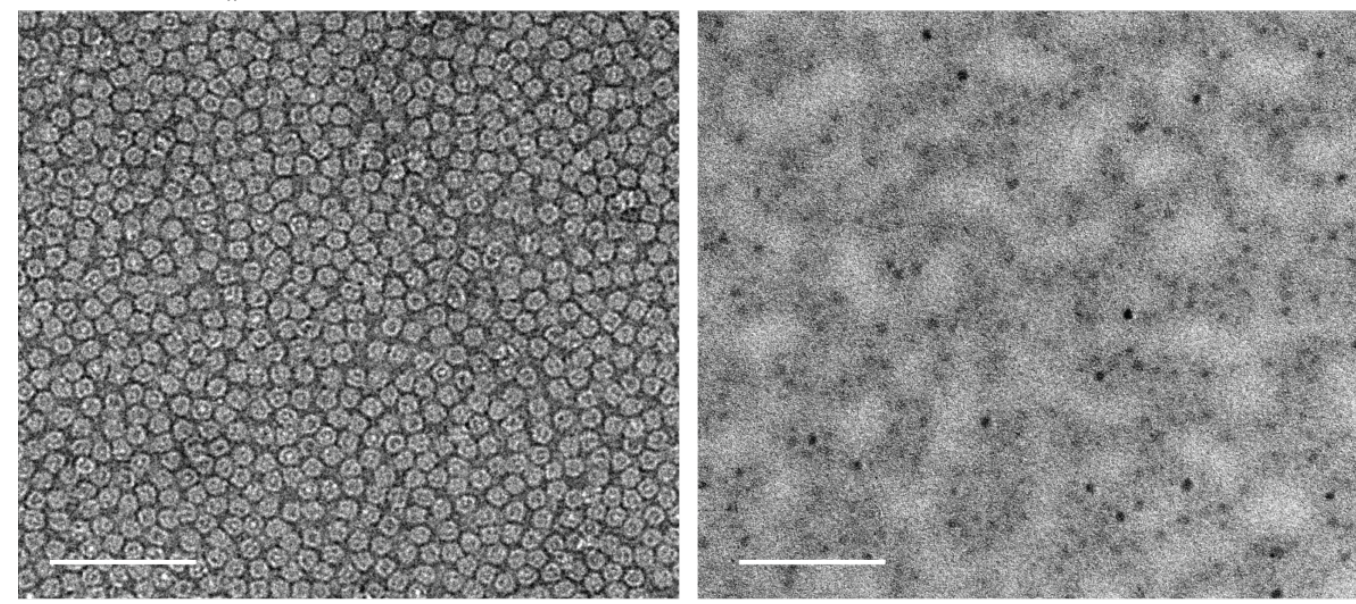

B Ftn ${ }^{\text {(pos) }} \mathrm{Co}_{3} \mathrm{O}_{4}$
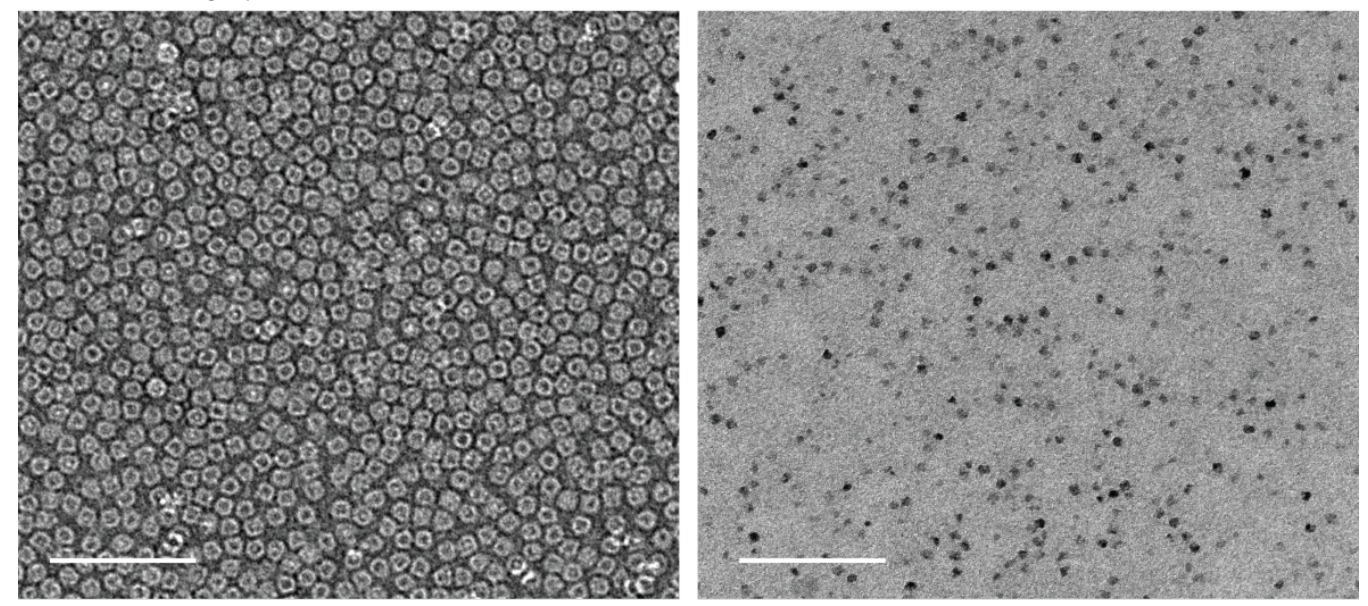

C Ftn ${ }^{\text {(pos) }} \mathrm{CeO}_{2}$
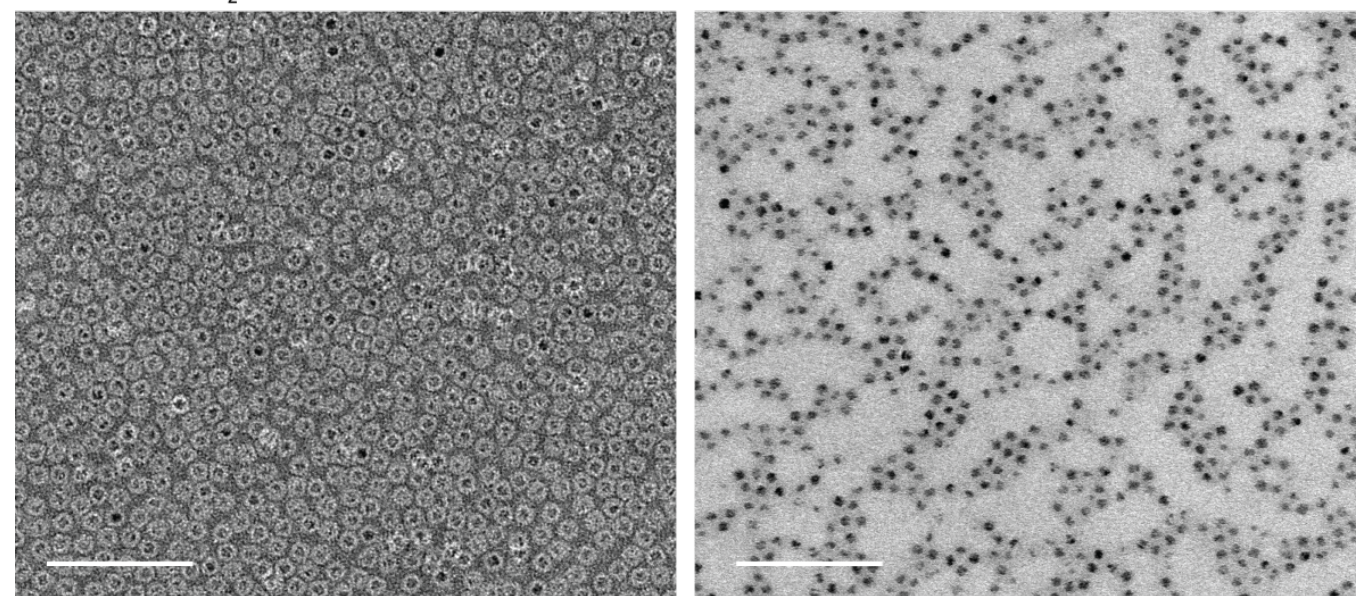

Figure S7. Protein container nanoparticle composites with Ftn ${ }^{\text {(pos) }}$. Left panel shows

electron micrographs with staining agent (uranyl acetate) applied, right panel without staining agent. (A) Iron oxide nanoparticles, (B) cobalt oxide nanoparticles, (C) cerium oxide nanoparticles. Scale bars are $100 \mathrm{~nm}$. 

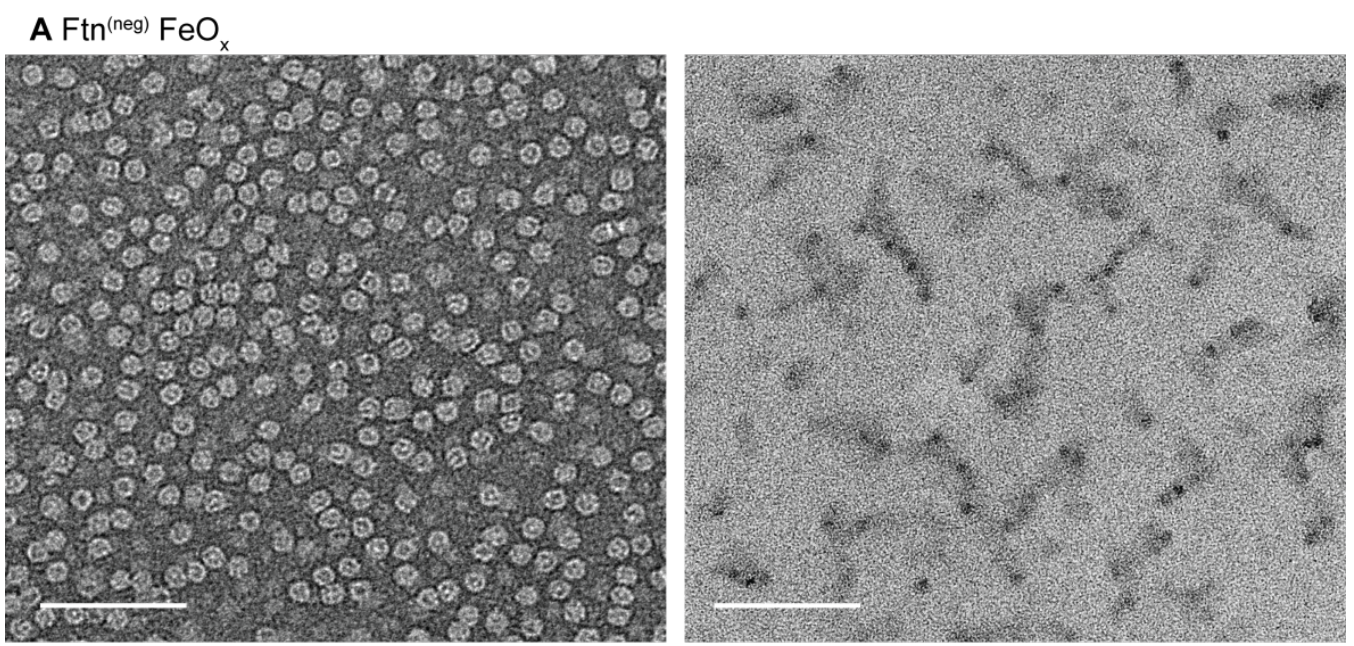

\section{B Ftn ${ }^{\text {(neg) }} \mathrm{Co}_{3} \mathrm{O}_{4}$}
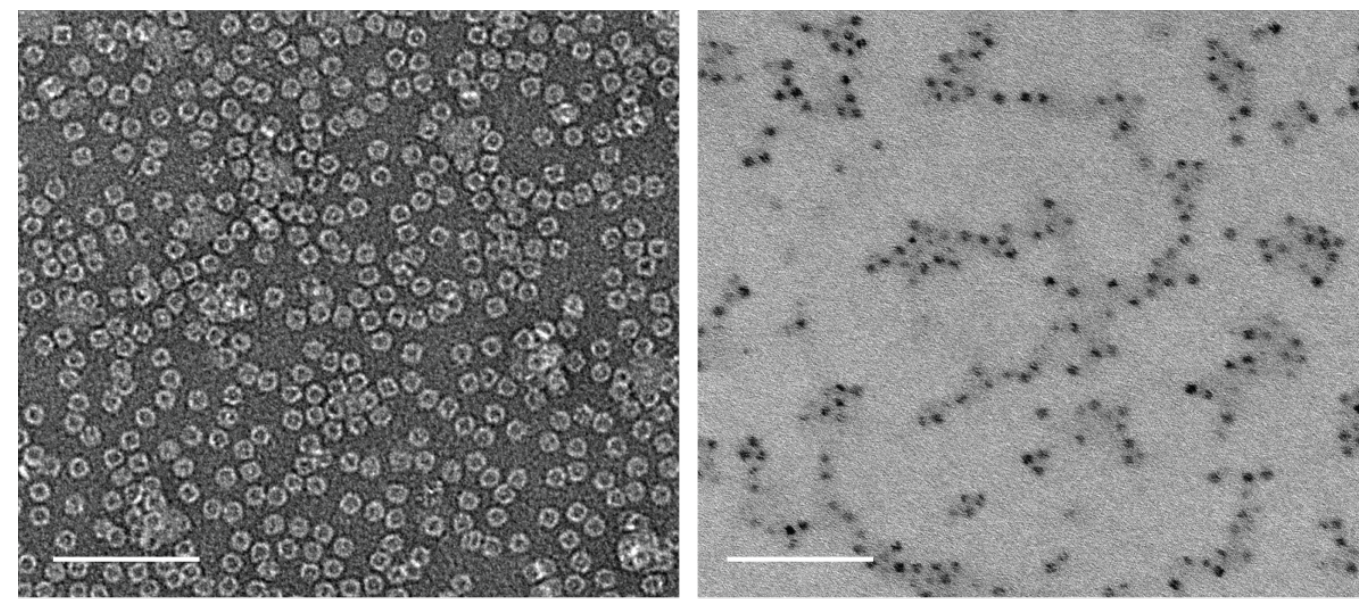

\section{Ftn ${ }^{\text {(neg) }} \mathrm{CeO}_{2}$}
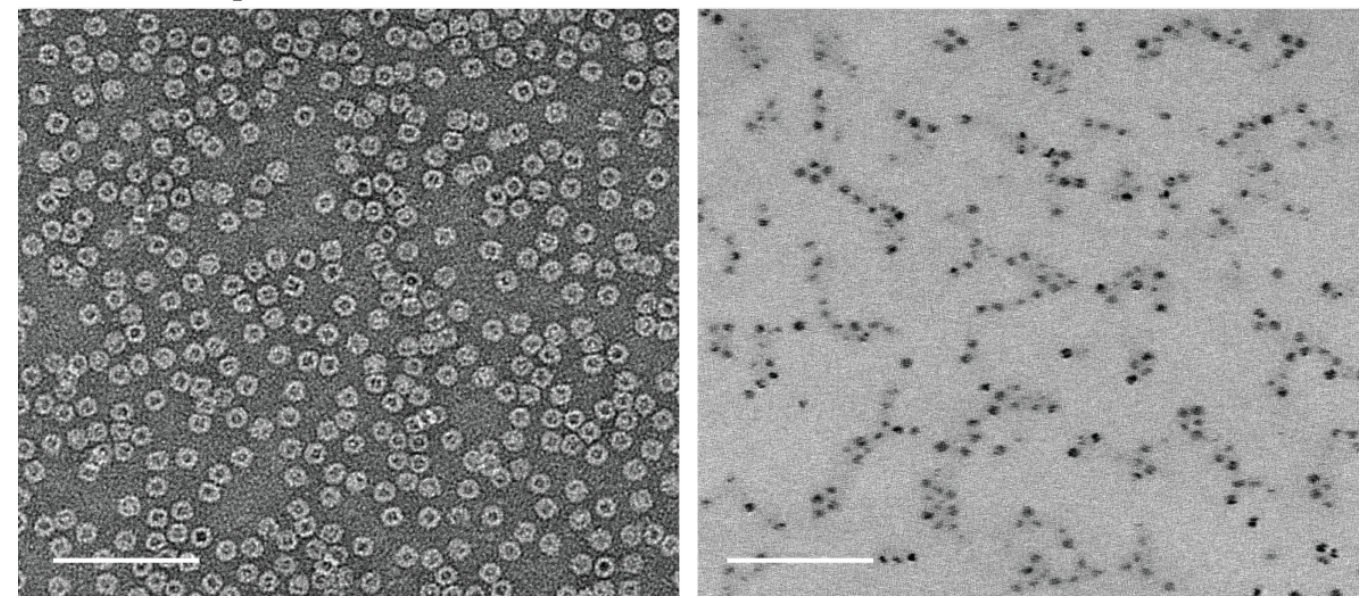

Figure S8. Protein container nanoparticle composites with $\mathrm{Ftn}^{\left({ }^{(n e g)}\right.}$. Left panel shows electron micrographs with staining agent (uranyl acetate) applied, right panel without staining agent. (A) Iron oxide nanoparticles, (B) cobalt oxide nanoparticles, (C) cerium oxide nanoparticles. Scale bars are $100 \mathrm{~nm}$. 
Table S2. Size of protein container nanoparticle composites. Protein shell size was determined from electron micrographs with staining agent applied. Nanoparticle core size was determined from unstained micrographs. For each sample 200 particles were measured. Analysis was carried out with ImageJ. ${ }^{[17]}$

\begin{tabular}{|c|c|c|c|}
\hline Variant & NP core type & Protein shell size (nm) & NP core size (nm) \\
\hline \multirow{3}{*}{$\mathrm{Ftn}^{(\text {pos })}$} & empty & $12.2 \pm 0.8$ & - \\
\cline { 2 - 4 } & $\mathrm{FeO}_{x}$ & $12.2 \pm 0.7$ & $4.9 \pm 1.0$ \\
\cline { 2 - 4 } & $\mathrm{Co}_{3} \mathrm{O}_{4}$ & $12.1 \pm 0.7$ & $5.3 \pm 1.0$ \\
\cline { 2 - 4 } & $\mathrm{CeO}_{2}$ & $12.2 \pm 0.7$ & $5.8 \pm 0.9$ \\
\hline \multirow{3}{*}{$\mathrm{Ftn}^{(\text {neg })}$} & $\mathrm{empty}^{*}$ & $12.0 \pm 0.6$ & - \\
\cline { 2 - 4 } & $\mathrm{FeO}_{x}$ & $12.0 \pm 0.6$ & $5.2 \pm 0.9$ \\
\cline { 2 - 4 } & $\mathrm{Co}_{3} \mathrm{O}_{4}$ & $12.3 \pm 0.7$ & $5.6 \pm 1.1$ \\
\cline { 2 - 4 } & $\mathrm{CeO}_{2}$ & $12.3 \pm 0.9$ & $5.5 \pm 1.0$ \\
\hline
\end{tabular}



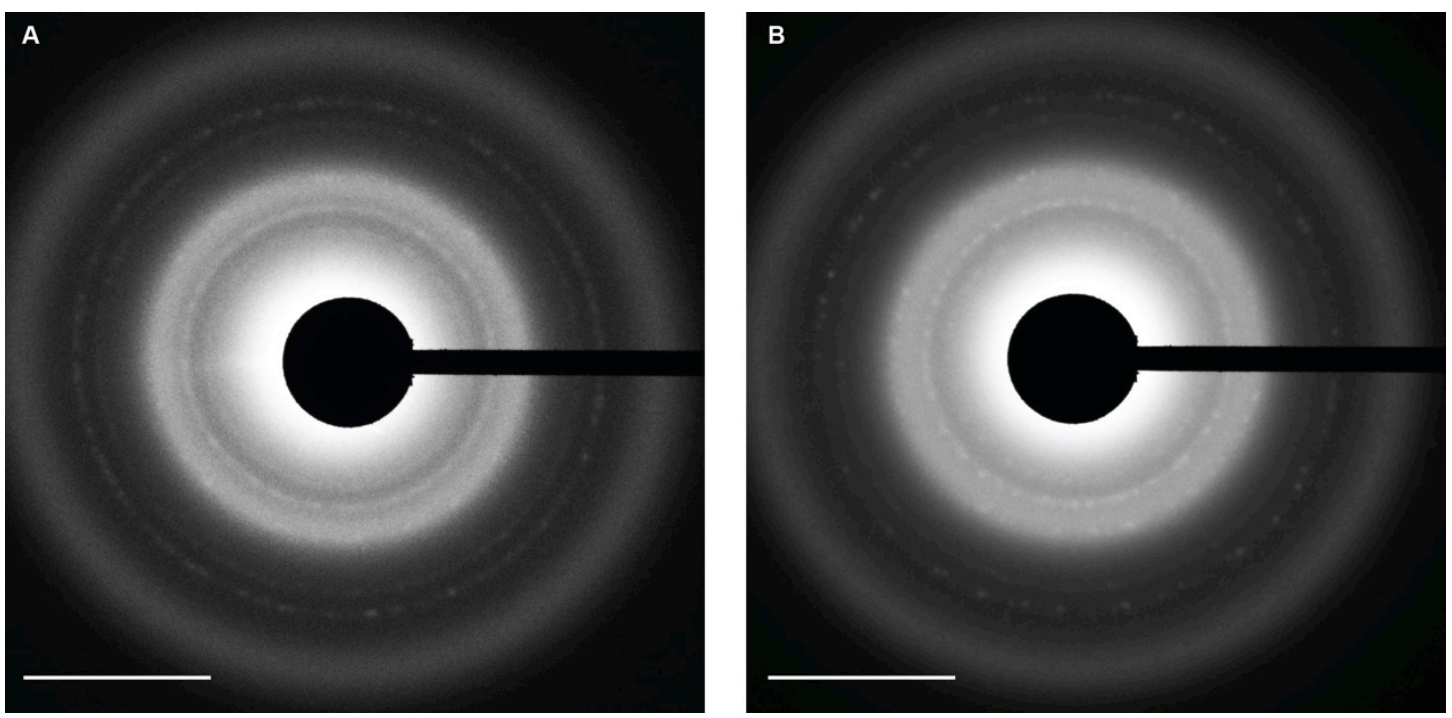

Figure S9. Selected area electron diffraction of cobalt oxide nanoparticles. Each diffraction pattern shows five distinctive rings for the protein container nanoparticle composites, at similar d-spacing for both protein containers, see Tab. S3. (A) Ftn ${ }^{\text {(pos) }}$ $\mathrm{Co}_{3} \mathrm{O}_{4}$, (B) $\mathrm{Ftn}^{(\text {neg) }} \mathrm{Co}_{3} \mathrm{O}_{4}$. Scale bar is $5 \mathrm{~nm}^{-1}$.

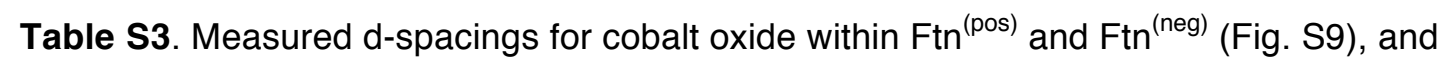
d-spacings for cobalt oxide $\left(\mathrm{Co}_{3} \mathrm{O}_{4}\right)$ and cobalt oxyhydroxide $(\mathrm{Co}(\mathrm{O}) \mathrm{OH})$, given in $\AA$. Only strong diffraction rings are tabulated.

\begin{tabular}{|c|c|c|c|c|}
\hline $\begin{array}{l}\text { Measured } \\
\text { d-spacing } \\
\text { for Ftn } \\
\text { (pos) }\end{array}$ & $\begin{array}{l}\text { Measured } \\
\text { d-spacing } \\
\text { for Ftn }^{(\text {neg) }}\end{array}$ & $\mathrm{Co}_{3} \mathrm{O}_{4}{ }^{[21]}$ & $\begin{array}{c}\mathrm{Co}(0) \mathrm{OH} \\
\text { (Heterogenite) }^{[22]} \\
\mathrm{SG}^{*}: \text { P63/mmc }\end{array}$ & $\begin{array}{c}\mathrm{Co}(\mathrm{O}) \mathrm{OH} \\
\text { (Heterogenite) }^{[23]} \\
\mathrm{SG}^{*}: \operatorname{R-3m}\end{array}$ \\
\hline 2.83 & 2.88 & 2.851 & 2.473 & 2.427 \\
\hline 2.43 & 2.48 & 2.432 & 2.380 & 2.311 \\
\hline 2.00 & 2.04 & 2.016 & 2.201 & 2.191 \\
\hline 1.54 & 1.57 & 1.552 & 2.156 & 1.974 \\
\hline 1.42 & 1.45 & 1.426 & 1.891 & 1.800 \\
\hline
\end{tabular}

* SG: space group 

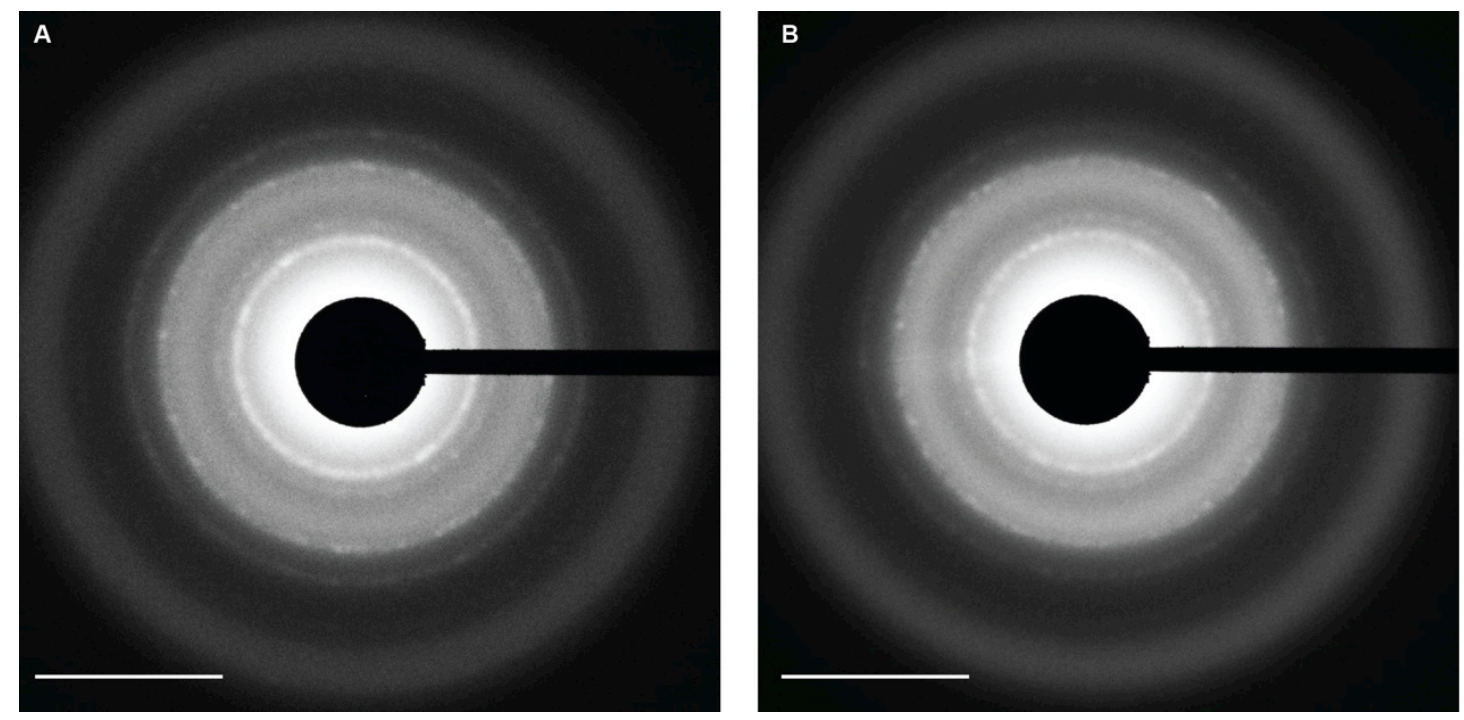

Figure S10. Selected area electron diffraction of cerium oxide nanoparticles. Each diffraction pattern shows four distinctive rings for the protein container nanoparticle composites, at similar d-spacing for both protein containers, see Tab. S4. (A) Ftn ${ }^{\text {(pos) }}$ $\mathrm{CeO}_{2}$, (B) $\mathrm{Ftn}^{(\text {neg) }} \mathrm{CeO}_{2}$. Scale bar is $5 \mathrm{~nm}^{-1}$.

Table S4. Measured d-spacings for cerium oxide within Ftn ${ }^{\text {(pos) }}$ and Ftn ${ }^{\text {(neg) }}$ (Fig. S10), and d-spacings for cerium dioxide $\left(\mathrm{CeO}_{2}\right)$, given in $\AA$. Only strong diffraction rings are tabulated.

\begin{tabular}{|c|c|c|}
\hline $\begin{array}{l}\text { Measured } \\
\text { d-spacing } \\
\text { for Ftn } \\
\text { (pos) }\end{array}$ & $\begin{array}{l}\text { Measured } \\
\text { d-spacing } \\
\text { for Ftn }^{(\text {neg) }}\end{array}$ & $\mathrm{CeO}_{2}{ }^{[24]}$ \\
\hline 3.14 & 3.12 & 3.123 \\
\hline 2.70 & 2.68 & 2.705 \\
\hline 1.93 & 1.91 & 1.913 \\
\hline 1.64 & 1.63 & 1.631 \\
\hline
\end{tabular}


Table S5. Selected nanoparticle combinations in binary crystals. Selected combinations include both protein containers empty (1), one container loaded with nanoparticles, the other empty (2-4), both containers loaded with the same nanoparticle type (5-6), and both containers loaded with different nanoparticle types (7-8).

\begin{tabular}{|c|c|c|c|c|}
\hline & $\#$ & Ftn ${ }^{\text {(pos) }}$ & & $\mathrm{Ftn}^{(\text {neg })}$ \\
\hline \multirow{8}{*}{$\begin{array}{l}\text { NP type in binary } \\
\text { superlattices }\end{array}$} & 1 & empty & I & empty \\
\hline & 2 & empty & I & $\mathrm{FeO}_{\mathrm{x}}$ \\
\hline & 3 & $\mathrm{CeO}_{2}$ & I & empty \\
\hline & 4 & empty & I & $\mathrm{Co}_{3} \mathrm{O}_{4}$ \\
\hline & 5 & $\mathrm{FeO}_{\mathrm{x}}$ & I & $\mathrm{FeO}_{\mathrm{x}}$ \\
\hline & 6 & $\mathrm{CeO}_{2}$ & I & $\mathrm{CeO}_{2}$ \\
\hline & 7 & $\mathrm{FeO}_{\mathrm{x}}$ & I & $\mathrm{CeO}_{2}$ \\
\hline & 8 & $\mathrm{CeO}_{2}$ & I & $\mathrm{Co}_{3} \mathrm{O}_{4}$ \\
\hline
\end{tabular}



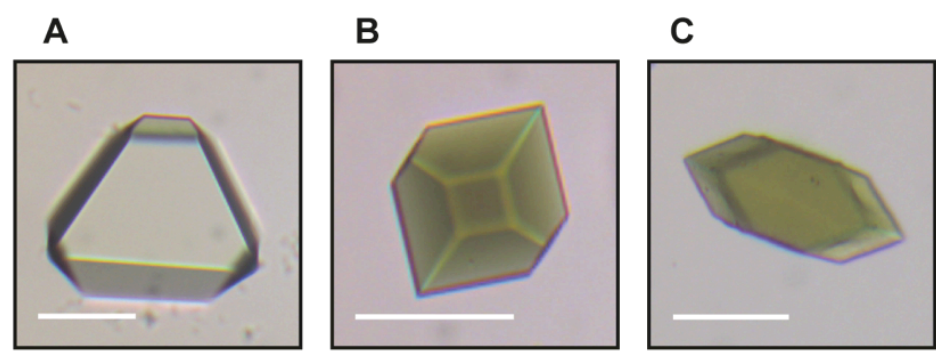

Figure S11. Microscopy images of binary protein-nanoparticle crystals. Optical

microscopy pictures of representative binary crystals from $\mathrm{Ftn}^{(\mathrm{pos})}$ and $\mathrm{Ftn}^{(\mathrm{neg})}$, filled with nanoparticles. (A) $\mathrm{Ftn}^{\text {(pos) }} \mathrm{CeO}_{2}$ and $\mathrm{Ftn}^{(\text {(neg) }}$ empty, (B) $\mathrm{Ftn}^{\left({ }^{\text {(pos })}\right.}$ empty and $\mathrm{Ftn}^{\text {(neg) }} \mathrm{Co}_{3} \mathrm{O}_{4}$, (C) $\mathrm{Ftn}^{\text {(pos) }} \mathrm{CeO}_{2}$ and $\mathrm{Ftn}^{(\text {neg) }} \mathrm{Co}_{3} \mathrm{O}_{4}$. Scale bars are $50 \mu \mathrm{m}$. Optical microscopy images of the crystallization drops are shown in Fig. 3 in the main text. 
A

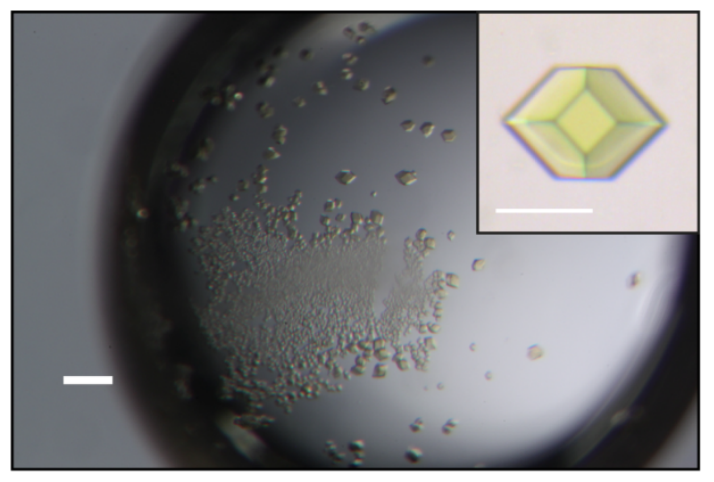

C

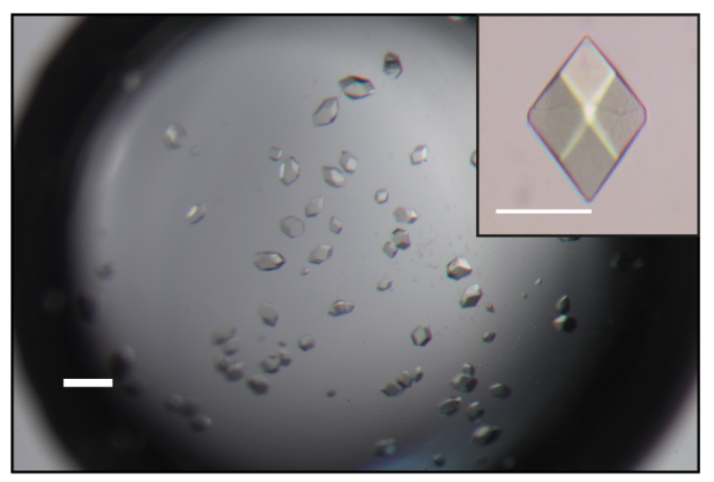

B

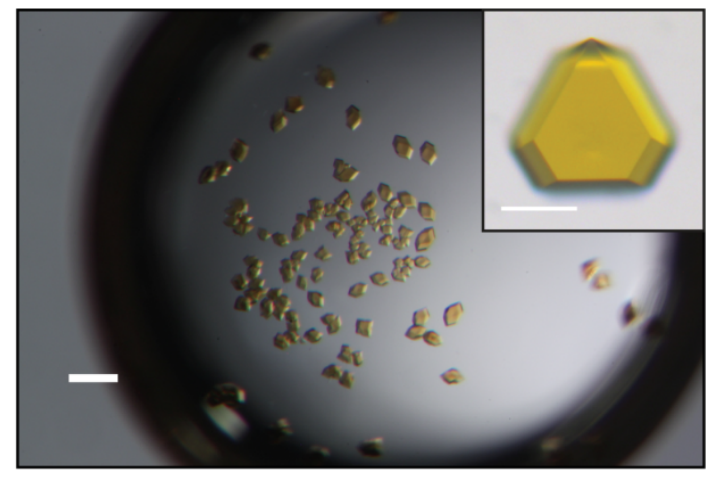

D

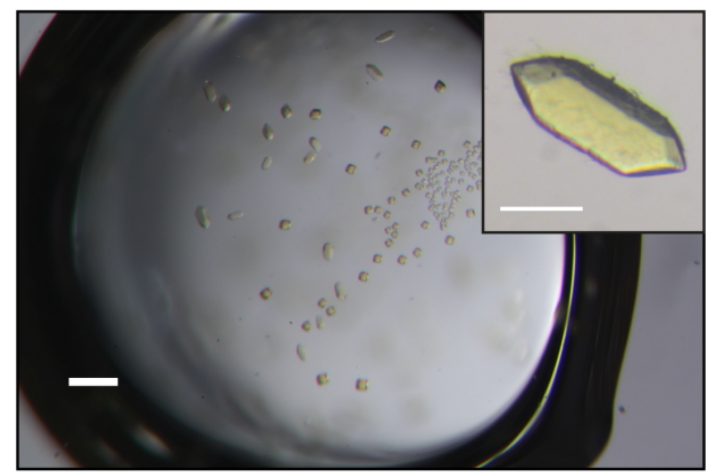

Figure S12. Microscopy images of binary protein-nanoparticle crystals. Optical microscopy pictures of binary crystals from $\mathrm{Ftn}^{\left({ }^{(\mathrm{pos})}\right.}$ and $\mathrm{Ftn}^{(\text {neg) }}$. Pictures show a crystallization drop from the manual plate setup and the insert a representative crystal. (A) $\mathrm{Ftn}^{\text {(pos) }}$ empty and $\mathrm{Ftn}^{\text {(neg) }} \mathrm{FeO}_{\mathrm{x}}$, (B) $\mathrm{Ftn}^{\text {(pos) }} \mathrm{FeO}_{\mathrm{x}}$ and $\mathrm{Ftn}^{(\text {neg })} \mathrm{FeO}_{\mathrm{x}},(\mathrm{C}) \mathrm{Ftn}^{(\text {pos })} \mathrm{CeO}_{2}$ and $\mathrm{Ftn}^{(\text {neg) }} \mathrm{CeO}_{2}$, (D) $\mathrm{Ftn}^{(\text {pos })} \mathrm{FeO}_{\mathrm{x}}$ and $\mathrm{Ftn}^{(\text {neg) }} \mathrm{CeO}_{2}$. Scale bars for the crystallization drops are $200 \mu \mathrm{m}$, for the single crystal images $50 \mu \mathrm{m}$. 

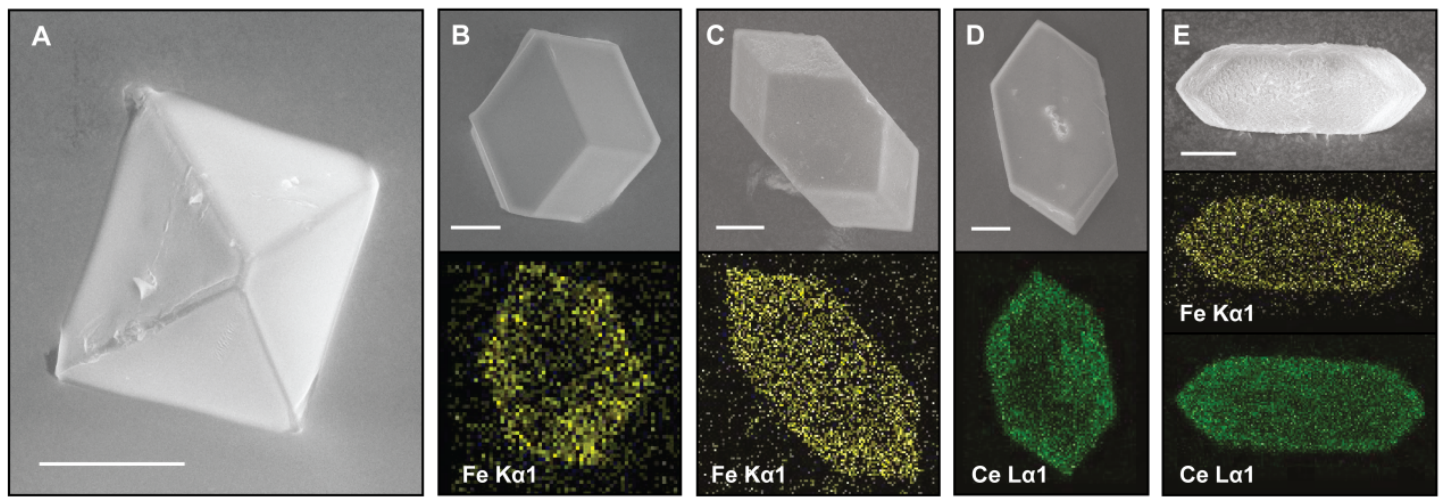

Figure S13. SEM analysis of binary crystals. For samples $(B)$ to $(E)$ the top panel shows the SEM image of a representative crystal and the bottom panel the EDX mapping. Crystals composed of (A) Ftn ${ }^{\text {(pos) }}$ empty and Ftn ${ }^{(\text {neg) }}$ empty, (B) Ftn ${ }^{\text {(pos) }}{ }^{\text {empty }}$ and $\mathrm{Ftn}^{(\text {neg })} \mathrm{FeO}_{\mathrm{x}}$, (C) $\mathrm{Ftn}^{(\text {pos })} \mathrm{FeO}_{\mathrm{x}}$ and $\mathrm{Ftn}^{(\text {neg })} \mathrm{FeO}_{\mathrm{x}}$, (D) $\mathrm{Ftn}^{\text {(pos) }} \mathrm{CeO}_{2}$ and $\mathrm{Ftn}^{(\text {neg) }} \mathrm{CeO}_{2}$, (E) $\mathrm{Ftn}^{(\text {pos })} \mathrm{FeO}_{\mathrm{x}}$ and $\mathrm{Ftn}^{(\text {neg) }} \mathrm{CeO}_{2}$. Scale bar for $(\mathrm{A})$ is $50 \mu \mathrm{m}$, for other panels $20 \mu \mathrm{m}$. 
Table S6. Cell parameters obtained from SAXS data

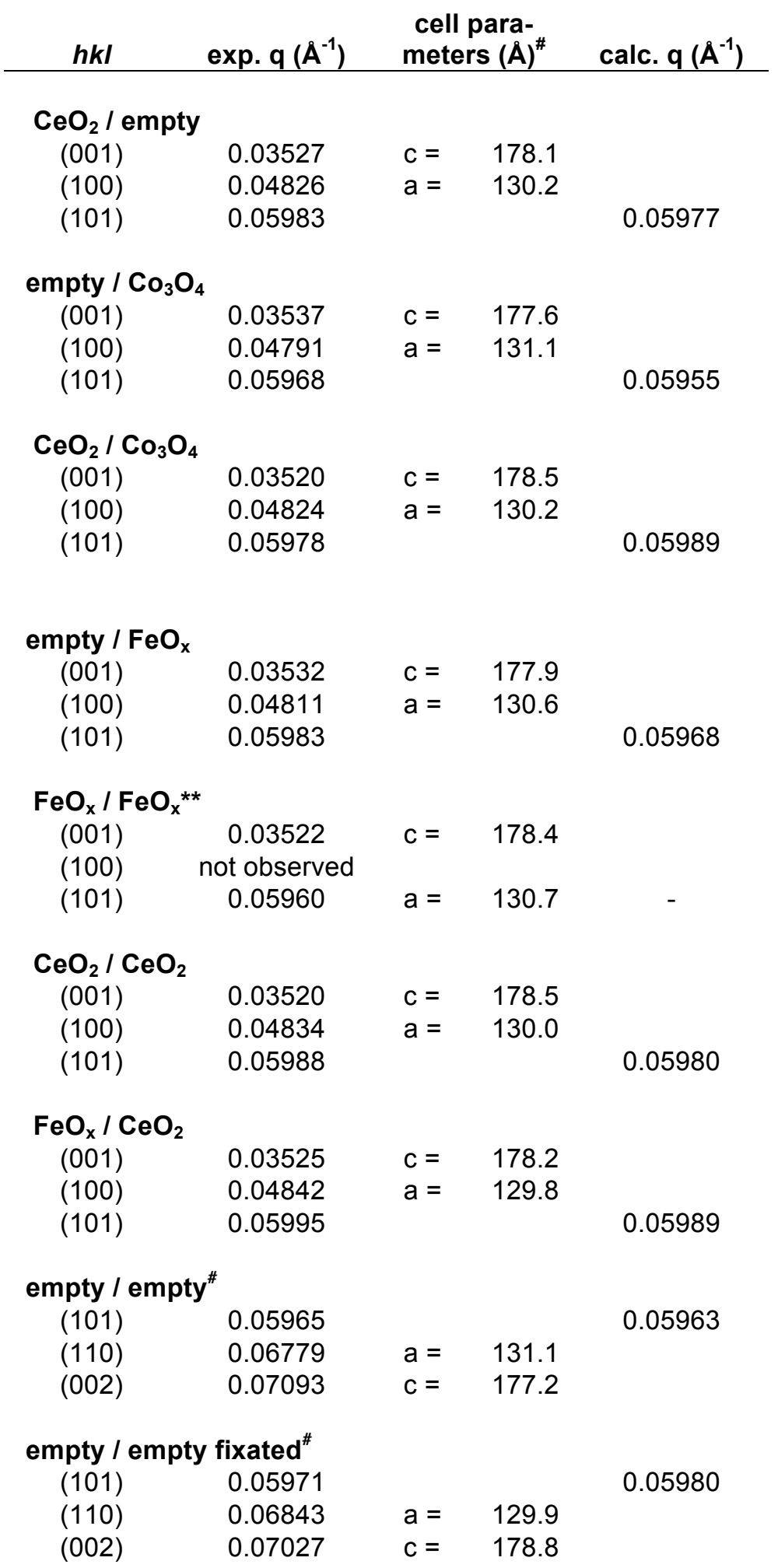

\footnotetext{
** Since reflection (100) was not observed (body-centered tetragonal lattice), reflection (101) was used to calculate cell constant $a$ based on eq. 4 and cell constant $c$.

\#Reflections (110) and (002) were used for the calculation of cell parameters, according to eq. 1
} 

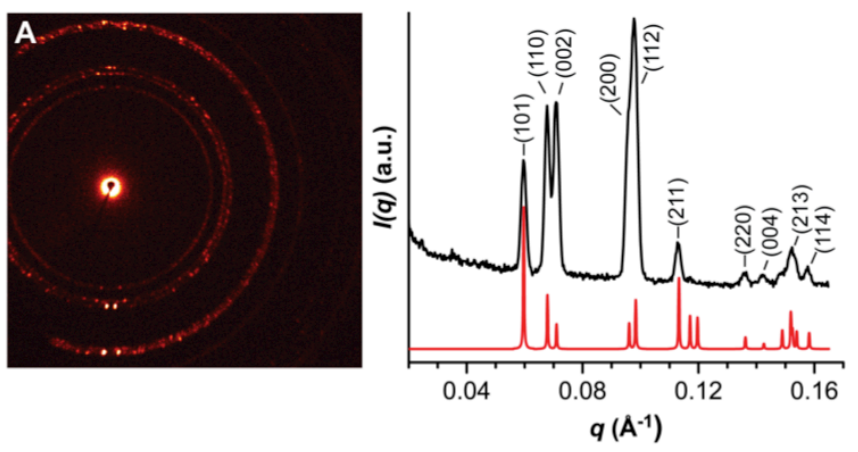

unfixated
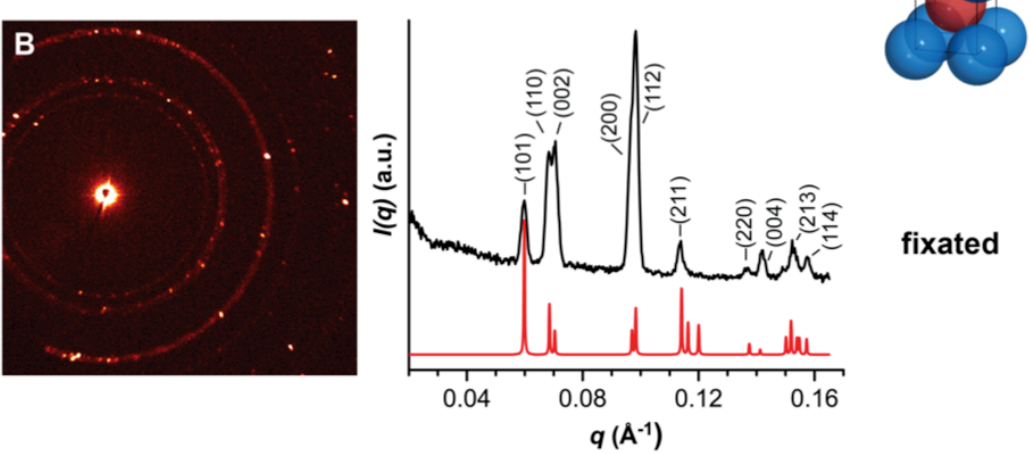

Figure S14. SAXS data of binary crystals composed of empty containers. 2D and radially averaged 1D SAXS data for crystals of empty protein containers. (A) Unfixated crystals, (B) crystals after fixation with glutaraldehyde. Experimental data are shown in black, and predicted scattering patterns are shown in red. Both samples show the same set of diffraction rings. 

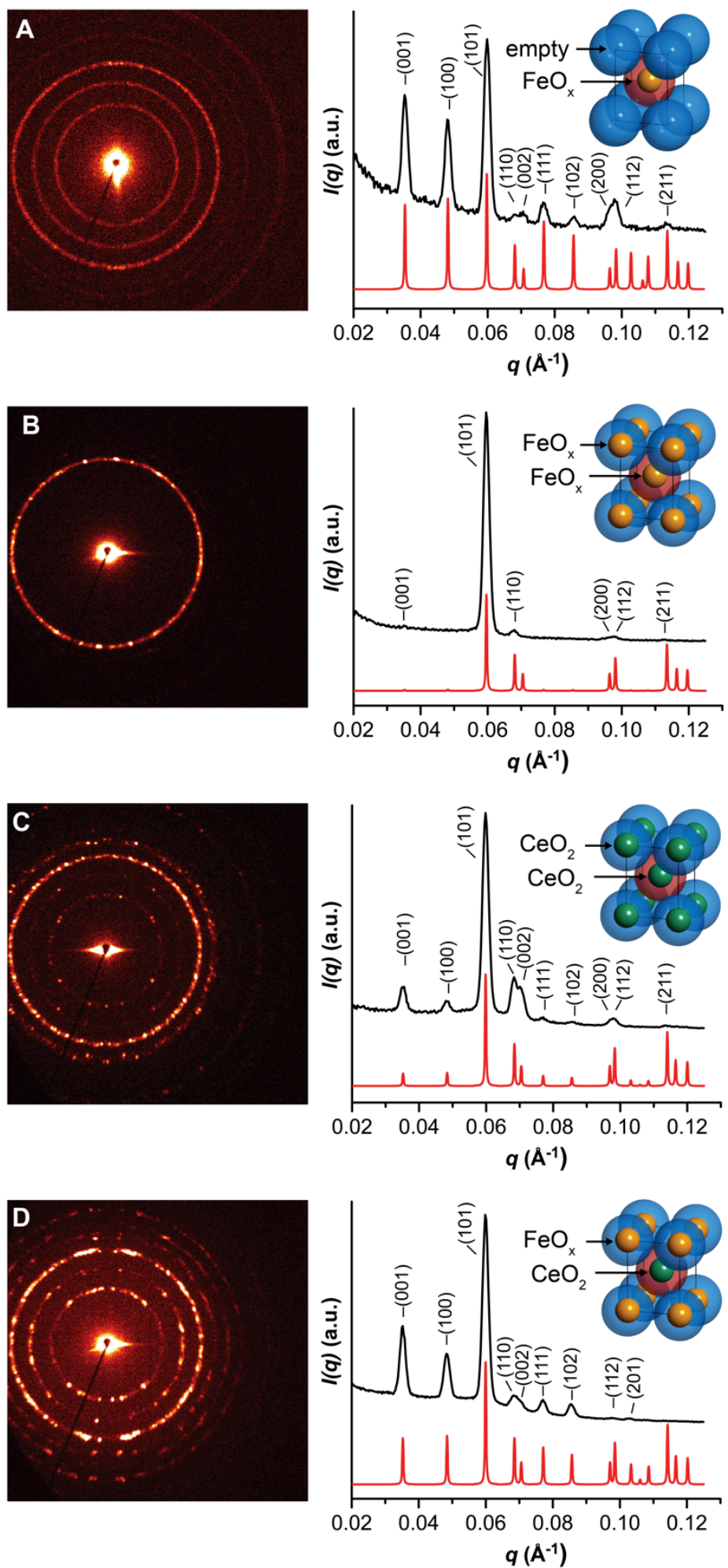

Figure S15. SAXS data of binary protein-nanoparticle crystals. 2D and radially

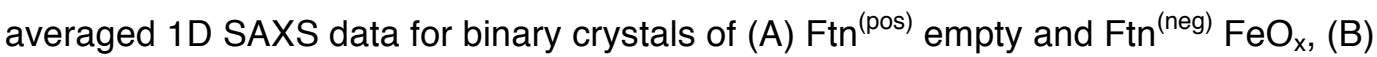
$\mathrm{Ftn}^{(\text {pos })} \mathrm{FeO}_{\mathrm{x}}$ and $\mathrm{Ftn}^{(\text {neg })} \mathrm{FeO}_{\mathrm{x}}$, (C) $\mathrm{Ftn}^{\text {(pos) }} \mathrm{CeO}_{2}$ and $\mathrm{Ftn}^{(\text {(neg) }} \mathrm{CeO}_{2}$, (D) $\mathrm{Ftn}^{\left({ }^{\text {(os) }}\right.} \mathrm{FeO}_{\mathrm{x}}$ and $\mathrm{Ftn}^{(\text {neg) }} \mathrm{CeO}_{2}$. Experimental data are shown in black, and predicted scattering patterns are shown in red. A unit cell of the corresponding crystal composition is shown. 